\title{
Dynamic Vibration Characteristic Analysis for the Power-Split Transmission System Based on Loaded Tooth Contact Analysis
}

\author{
Hao Dong, Yan Cao, and Zhou Fang \\ School of Mechanical and Electronic Engineering, Xian Technological University, Xi'an 710021, China \\ Correspondence should be addressed to Hao Dong; donghaofane@sina.com
}

Received 20 July 2014; Revised 7 September 2014; Accepted 9 October 2014

Academic Editor: Luigi Garibaldi

Copyright (C) 2015 Hao Dong et al. This is an open access article distributed under the Creative Commons Attribution License, which permits unrestricted use, distribution, and reproduction in any medium, provided the original work is properly cited.

\begin{abstract}
In order to solve the dynamic vibration characteristics of the power-split transmission system, the system of the dynamic mechanical model is established. Firstly, according to the theoretical analysis method of the tooth contact analysis (TCA) and loaded tooth contact analysis (LTCA), the actual meshing process of each gear pair is simulated, and the time-varying mesh stiffness excitation is obtained, which can improve the numerical precision. Next, by using the lumped mass method, the bending-torsional coupling three-dimensional dynamical model of the power-split transmission is established. The identical dimensionless equations are deduced by eliminating the effect of rigid displacement and the method of dimensional normalization. Next, the frequency domain and time domain responses of this system are obtained. The dynamic load change characteristics of each gear pair are analyzed. The results show that establishment, solution, and analysis of the system dynamics model could provide a basis for the dynamic design and have an important significance for the dynamic efficiency analysis and dynamic performance optimization design of the power-split transmission. Through theoretical data compared with the experimental data, we verified the correctness of the method proposed.
\end{abstract}

\section{Introduction}

A power-split transmission adopts the power-split technology; it can realize the power split in four ways. Due to compact structure of power-split transmission, it is designed to meet the operating conditions with high speed and overloaded operation. It has a broad application prospect in the aerospace and marine industry. The vibration and dynamic of power-split transmission system are of important in the application; it is directly related to the transmission system reliability and security.

Many researchers [1-4] had already done lots of analysis on the load-sharing systems with elastic supports at abroad and home. Kish $[5,6]$ has reported on the development and testing of a power-split transmission that featured a torsional elastomeric load-sharing device. A companion study to develop a method to analyze and optimize the load sharing of split-path gear boxes has also been completed; the results of that study are reported separately by Krantz et al. [7-9]. The effect of time-varying mesh stiffness, friction static transmission error, and elastic supporting has been considered. Dynamic load-sharing behavior, the load-sharing coefficient of star gear trains with effect of each level of connection stiffness, and star gear eccentric errors have been analyzed by Guo et al. [10]. Some other scholars [11-19] have also conducted researches on the power-split transmission.

However, much of recent research on power-split transmission systems minimized the influence of gear surface tooth contact; most of these researches just adopted equivalent average mesh stiffness of a gear pair to express progress of load research and could not accurately reflect a real meshing process. In this paper, a real meshing process of gear pairs is dispersed into a limited meshing point, according to the theoretical analysis method of tooth contact analysis (TCA) and loaded tooth contact analysis (LTCA). Statics characteristic of each meshing position is analyzed. The mechanical properties are obtained. This method can improve accuracy of the calculation.

In this paper, in order to obtain good dynamic performance of double road power-split transmission systems, 
the lumped parameter method is used to establish the bend-torsion coupling dynamic model. Then, the differential equation is solved to obtain the frequency domain and time domain response characteristics and the dynamic load coefficient of the system. Through the analysis and solution, it will help to further understand the dynamic characteristics of the system. It will provide a theoretical basis for the design and manufacturing of dual power-split transmission. It will have a great significance to the reasonable design and successful use for the dual power-split transmission system.

\section{Dynamics Model Building}

Figure 1 is a schematic diagram of the three-dimensional structure of power-split transmission system. The system adopts power-split technology. The power is from the input shaft 1. Level I adopts helical gears. Level II adopts spur gear. Two torsional axes are used to link the two levels of transmission. The two gears 5 of level II simultaneously mesh big gear 6 of level II. This transmission system can further effectively solve the drive big torque and speed ratio.

Lumped parameter method is adopted to establish the dynamic model of bend-torsion coupling. Dynamic model can be expressed in Figure 2. Here, $T_{\text {in }}$ is input torque; $T_{\text {out }}$ is output torque; $K_{i j}(i=1,4,5 ; j=2,3,6)$ is time-varying mesh stiffness; $C_{i j}$ is meshing damping; $\varphi_{i}$ and $\varphi_{j}$ are torsion angle; $e(t)_{i j}$ is integrated error; $M_{i}$ is moment of inertia concentrated mass; $k_{24}$ and $k_{35}$ are torsional rigidity; $c_{24}$ and $c_{35}$ are torsional damper.

The meshing force can be represented by

$$
\begin{aligned}
P_{i j}=K_{i j}( & r_{b i} \varphi_{i}-r_{b j} \varphi_{j}+\left(x_{i}-x_{j}\right) \cos \zeta_{i j}+\left(y_{i}-y_{j}\right) \sin \zeta_{i j} \\
& +\left(\Delta A x_{i}-\Delta A x_{j}\right) \cos \zeta_{i j} \\
& \left.+\left(\Delta A y_{i}-\Delta A y_{j}\right) \sin \zeta_{i j}-e_{i j}(t)\right) .
\end{aligned}
$$

The damping force can be represented by

$$
\begin{aligned}
D_{i j}=C_{i j}\left(r_{b i} \dot{\varphi}_{i}-r_{b j} \dot{\varphi}_{j}+\left(\dot{x}_{i}-\dot{x}_{j}\right) \cos \zeta_{i j}+\left(\dot{y}_{i}-\dot{y}_{j}\right) \sin \zeta_{i j}\right. \\
+\left(\Delta A \dot{x}_{i}-\Delta A \dot{x}_{j}\right) \cos \zeta_{i j} \\
\left.+\left(\Delta A \dot{y}_{i}-\Delta A \dot{y}_{j}\right) \sin \zeta_{i j}-\dot{e}_{i j}(t)\right)
\end{aligned}
$$

where $x_{i}$ and $x_{j}$ are displacement deformation along the $x$ axis; $y_{i}$ and $y_{j}$ are displacement deformation along the $y$-axis; $\triangle A x_{i}$ and $\triangle A x_{j}$ are the amplitudes of errors along the $x$-axis; $\Delta A y_{i}$ and $\Delta A y_{j}$ are the amplitudes of errors along the $y$-axis, respectively, for the pinion $i$ and gear $j ; \zeta_{i j}$ is actual operating pressure positive angle; $r_{b i}$ is the base radius.

The dynamics differential equation of lateral-bending vibration can be represented by

$$
\begin{aligned}
& \sum\left[\left(P_{i j}+D_{i j}\right) \cdot \cos \zeta_{i j}\right]+M_{i} \ddot{x}_{i}+C_{x i} \dot{x}_{i}+K_{x i} x_{i}=0, \\
& \sum\left[\left(P_{i j}+D_{i j}\right) \cdot \sin \zeta_{i j}\right]+M_{i} \ddot{y}_{i}+C_{y i} \dot{y}_{i}+K_{y i} y_{i}=0,
\end{aligned}
$$

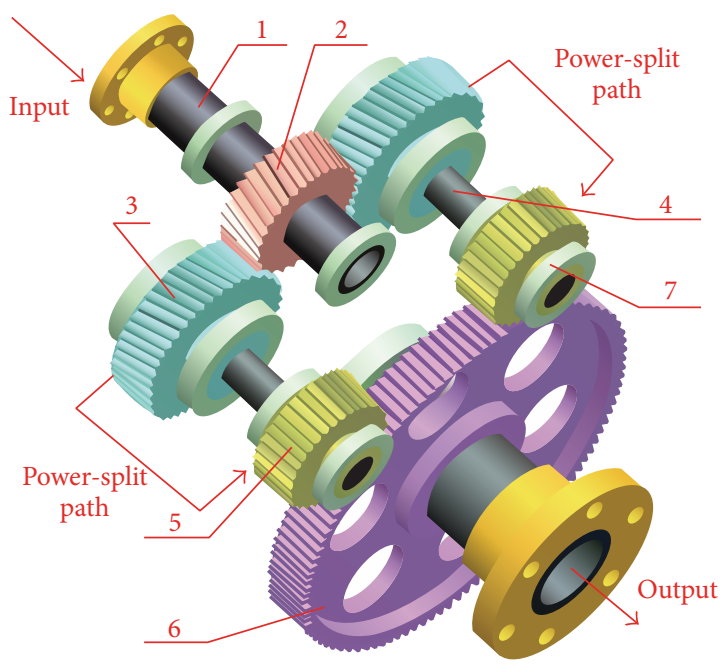

FIGURE 1: Example of a power-split transmission design with power paths. Illustration of (1) input shaft, (2) I-stage helical pinion, (3) I-stage helical gear, (4) torsion shaft, (5) II-stage spur pinion, (6) IIstage spur gear, and (7) II-stage spur pinion.

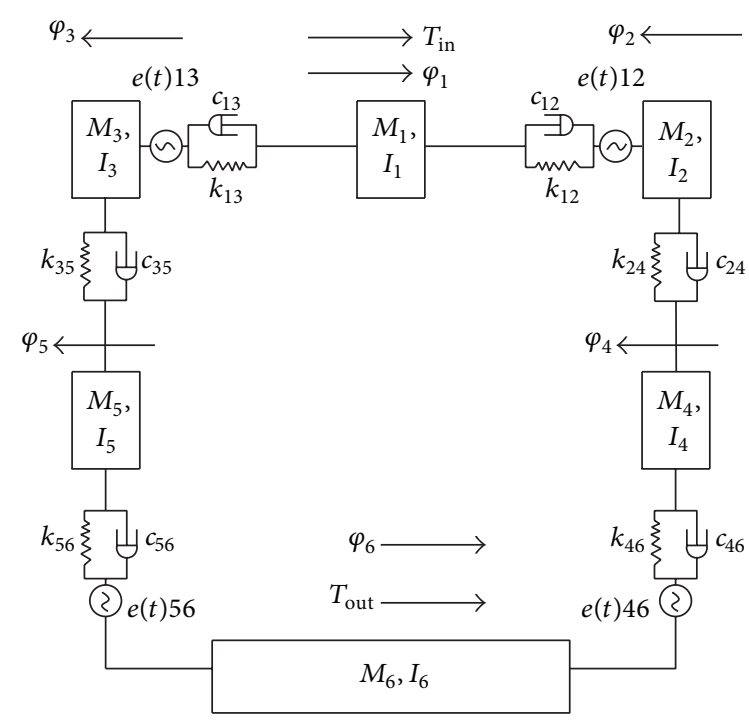

FIGURE 2: Schematic of mechanical structure model.

where $K_{x i}$ and $K_{y i}$ are the equivalent supporting rigidity; $C_{x i}$ and $C_{y i}$ are the equivalent bearing damping; $\ddot{x}_{i}, \dot{x}_{i}$, and $x_{i}$ are the transverse vibration acceleration, velocity, and displacement along $x$-direction; $\ddot{y}_{i}, \dot{y}_{i}$, and $y_{i}$ are the transverse vibration acceleration, velocity, and displacement along $y$-direction.

The angular displacement $\left(u_{i}=r_{i} \varphi_{i}\right)$ of generalized coordinates is translated into the line displacement. The differential equations of torsional direction can be represented by

$$
m_{\mathrm{eq}, 1} \ddot{u}_{1}+\left(P_{12}+D_{12}+P_{13}+D_{13}\right)=\frac{T_{\text {in }}}{r_{1} \cos a_{n}},
$$




$$
\begin{gathered}
m_{\mathrm{eq}, 2} \ddot{u}_{2}-\left(P_{12}+D_{12}\right)+\frac{c_{24}}{r_{b 2}}\left(\frac{\dot{u}_{2}}{r_{b 2}}-\frac{\dot{u}_{4}}{r_{b 4}}\right) \\
+\frac{k_{24}}{r_{b 2}}\left(\frac{u_{2}}{r_{b 2}}-\frac{u_{4}}{r_{b 4}}\right)=0 \\
m_{\mathrm{eq}, 3} \ddot{u}_{3}-\left(P_{13}+D_{13}\right)+\frac{c_{35}}{r_{b 3}}\left(\frac{\dot{u}_{3}}{r_{b 3}}-\frac{\dot{u}_{5}}{r_{b 5}}\right) \\
+\frac{k_{35}}{r_{b 3}}\left(\frac{u_{3}}{r_{b 3}}-\frac{u_{5}}{r_{b 5}}\right)=0, \\
m_{\mathrm{eq}, 4} \ddot{u}_{4}+\left(P_{46}+D_{46}\right)-\frac{c_{24}}{r_{b 4}}\left(\frac{\dot{u}_{2}}{r_{b 2}}-\frac{\dot{u}_{4}}{r_{b 4}}\right) \\
-\frac{k_{24}}{r_{b 4}}\left(\frac{u_{2}}{r_{b 2}}-\frac{u_{4}}{r_{b 4}}\right)=0, \\
m_{\mathrm{eq}, 5} \ddot{u}_{5}+\left(P_{56}+D_{56}\right)-\frac{c_{35}}{r_{b 5}}\left(\frac{\dot{u}_{3}}{r_{b 3}}-\frac{\dot{u}_{5}}{r_{b 5}}\right) \\
-\frac{k_{35}}{r_{b 5}}\left(\frac{u_{3}}{r_{b 3}}-\frac{u_{5}}{r_{b 5}}\right)=0 \\
m_{\mathrm{eq}, 6} \ddot{u}_{6}-\left(P_{46}+D_{46}\right)-\left(P_{56}+D_{56}\right)=-\frac{T_{\mathrm{out}}}{r_{b 6}}
\end{gathered}
$$

where $m_{\mathrm{eq}, i}\left(m_{\mathrm{eq}, i}=I_{i} / r_{b i}^{2}\right)$ is equivalent mass. The variablestep four-order Runge-Kutta method is used to solve (2) and (3). $t=\tau w_{n}$ is the definition of dimensional time. $b_{c}$ is displacement nominal scale.

The equations (2) and (3) are processed by the dimensional normalization.

Due to the influence of the initial value, the initial transient response cycles are deleted. Then, vibration responses of displacement, velocity, and acceleration are calculated. By using the fast Fourier transform (FFT) method, the frequency responses of displacement, velocity, and acceleration are derived. Finally, the dynamic load coefficient of the system is calculated.

The results of dynamic response characteristics are generated into (1) to get dynamic load. Dynamic load coefficient $(K D)$ can be expressed by

$$
\left[\begin{array}{ll}
K D_{46} & K D_{56}
\end{array}\right]^{T}=\frac{\left[\begin{array}{ll}
\max P_{46} & \max P_{56}
\end{array}\right]^{T}}{\left[\left(T_{\text {in }} / 2\right) i_{12}\right]}
$$

The dynamic load coefficient (KD) directly reflects the dynamic response of the system. The vibration of the system is more obvious as the dynamic load coefficient get bigger.

\section{Time-Varying Mesh Stiffness Based on the LTCA}

Under the external load, the torsional angle of tooth will be changed. The change of torsional angle consists of geometry transmission errors, bending deformations, and contact

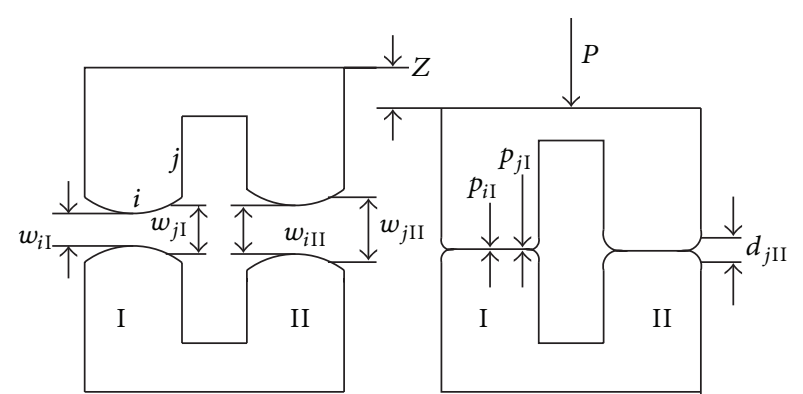

FIGURE 3: Load tooth contact analysis model.

deformations of tooth [15]. Functional relations between $\Delta \varphi_{i j}\left(T_{i j}(k)\right)$ and $T_{i j}(k)$ are expressed by

$$
\begin{aligned}
\Delta \varphi_{i j}\left(T_{i j}(k)\right) & =\delta_{1}(T(k))+\delta_{2}[T(k)]+\delta_{3}[T(k)] \\
& =a+b T_{i j}(k)+c T_{i j}(k)^{2 / 3},
\end{aligned}
$$

where $\delta_{1}, \delta_{2}$, and $\delta_{3}$ are the deformations of torsional angle; $T_{i j}(k)(k=1,2, \ldots, 5)$ is the torque of the $k$ th meshing position in a meshing cycle; $a, b$, and $c$ are constants.

The LTCA (load tooth contact analysis) models are shown in Figure 3, where the two pairs of teeth which contacted each other at a specific moment in the meshing cycle are denoted by I and II. The tooth surface curve is vertical along the relative principal direction in the normal plane, which is shown in Figure 3. $i_{k}(k=\mathrm{I}, \mathrm{II})$ is the contact point; $j_{k}$ is a point along the relative principal direction [20].

Under the load $P$, the driving gear goes through an approach $Z$. Due to the tooth deformation, contact load will become distributed. After contact deformation, the state can be described by the following equation for the tooth pair $k$ :

$$
[f]_{k}\left[p_{j}\right]_{k}+[w]_{k}=[Z]+\left[d_{j}\right]_{k},
$$

where $k=\mathrm{I}, \mathrm{II} ;\left[p_{j}\right]_{k}=\left[p_{1}, p_{2}, \ldots, p_{j k}, \ldots, p_{n k}\right]^{T} ;\left[d_{j}\right]_{k}=$ $\left[d_{1}, d_{2}, \ldots, d_{j k}, \ldots, d_{n k}\right]^{T} ;[Z]=Z_{k}[1,1, \ldots, 1, \ldots, 1]^{T}$; $[f]_{k}$ is the normal flexibility coefficient matrix of the gear pair $k ; p_{j}\left(j=1,2, \ldots, n_{k}\right)$ is the contact load supported at point $j$ of the tooth pair $k ; d_{j}\left(j=1,2, \ldots, n_{k}\right)$ is the final tooth clearance at point $j ; Z_{k}$ is the tooth approach. Apparently, the contact force $p_{j}\left(j=1,2, \ldots, n_{k}\right)$ must satisfy the following conditions:

$$
\sum_{j=1}^{n} p_{j \mathrm{I}}+\sum_{j=1}^{n} p_{j \mathrm{II}}=P
$$

where if $\left[p_{j}\right]_{k}>0$, then $[d]_{j k}=0$; if $\left[p_{j}\right]_{k}=0$, then $[d]_{j k}>0$. $f, P$, and $w$ are known. The contact forces $\left[p_{j}\right]_{k}$, final tooth clearance $[d]_{j k}$, and tooth approach $[Z]$ are unknown.

The known parameters $(f, P, w)$ and unknown parameters $(p, d, Z)$ constitute a nonlinear program model. According to the tooth approach $Z_{k}$, the following objective function is established by

$$
\text { Minimize }[p]^{T}\{[F][p]+[w]-[Z]\} \text {. }
$$




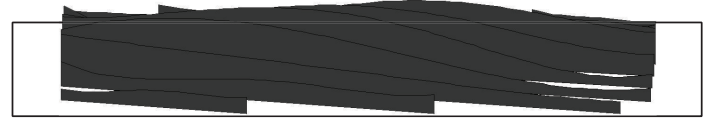

(a)

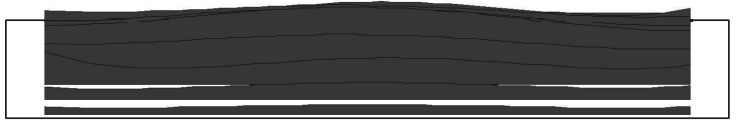

(b)

FIGURE 4: Load distribution on the tooth surface. Illustration of (a) I-stage helical gear pairs and (b) II-stage spur gear pairs.

Equations (8) and (9) represent a constrained nonlinear programming problem, which is solved by the modified simplex method.

The objective function (9) forms a nonlinear programming model with functions (7) and (8) as constraint conditions [14]:

$$
\begin{array}{ll}
\text { Min } & \sum_{j=1}^{2 n+1} X_{j} \\
& -[F][p]+[Z]+[d]+[X]=[w] \\
\text { S.t. } & {[e]^{T}[p]+X_{2 n+1}=P} \\
& p_{j} \geq 0, \quad d_{j} \geq 0, \quad Z \geq 0, \quad X_{j} \geq 0 ; \\
& p_{j}=0 \quad \text { or } \quad d_{j}=0,
\end{array}
$$

where $X_{j}(j=1,2, \ldots, 2 n+1)$ is the artificial variables; $[e]$ of each element is equal to 1 .

The corresponding angular error $\Delta \varphi_{i j}\left(T_{i j}(k)\right)$ is determined by

$$
\Delta \varphi_{i j}\left(T_{i j}(k)\right)=\frac{\Delta \delta_{i j}\left(T_{i j}(k)\right)}{r_{b i}} \cdot \cos \xi_{i} .
$$

Here, $\xi_{i}$ is the helix angle.

The load distribution on the contact lines of the tooth surface is shown in Figure 4.

The tooth approach $Z$ solved from the nonlinear programming problem for each contact position is actually the loaded tooth transmission errors as the amount of linear displacement error $\left(\Delta \delta_{i j}\right)$ of the driven gear along the contact normal (the line of action). The corresponding angular transmission error $\left(\Delta \varphi_{i j}\left(T_{i j}(k)\right)\right)$ under load for the contact position is determined by reversing (5). The column vector $[p]$ is solved from the programming problem that represents the discrete distribution of the contact load along the contact line that coincides with the relative principal direction.

By solving (5), we can obtain the coefficient of $a, b$, and $c$. Then, functional relations between loaded transmission errors and some nominal load of $T_{i j}(k)$ may be proposed. The calculation curves are supplied in a meshing cycle. The timevarying mesh stiffness is represented by

$$
K_{i j}(k)=\frac{T_{i j}(k)}{r_{i} \cos \alpha_{n}} \cdot \frac{1}{r_{b i} \Delta \varphi_{i j}\left(T_{i j}(k)\right)} .
$$

The mesh stiffness could reflect real meshing elastic properties at the meshing position more directly. The discrete value of meshing stiffness is fitted by the polynomial and

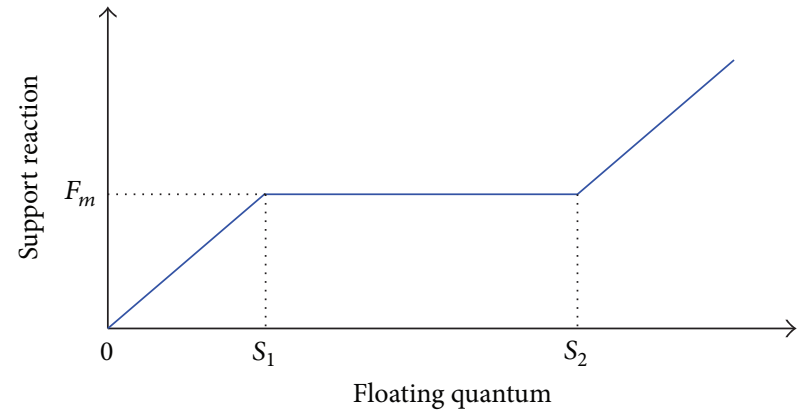

FIGURE 5: The schematic of supporting rigidity.

through the Fourier series transformation to spread out into a periodic function.

\section{Spline Clearance Floating}

In order to improve the uniform load distribution of the power-split transmission system and to solve the problem that elastic torsion shaft cannot completely satisfy the loadsharing characteristics, a structure of level I pinion floating is proposed.

Level I floating pinion is installed on one end of input shaft with high speed characteristics. It is connected with output components through a short spline. The spline can transmit the torque. However, floating pinion cannot completely float freely under the constraint of spline coupling. The supporting rigidity of floating pinion can be described in Figure 5.

In the process of the spline transmit torque, friction will be produced between internal and external spline. $F_{m}=\tau F_{m}$ is friction; here, $F_{m}$ is the positive pressure between internal and external spline and $\tau$ is friction coefficient. The floating quantum can be represented by

$$
\bar{D} r_{i}=\sqrt{\left(\bar{X}_{i}^{(n) 2}+\bar{Y}_{i}^{(n) 2}\right)} .
$$

Here, $\bar{X}_{i}^{(n)}$ and $\bar{Y}_{i}^{(n)}$ are the floating quantum along the $x$ direction and $y$-direction, respectively; $n$ is the iterations.

The floating pinion is affected by both of the engaging force of the two associated gears and support reaction of spline coupling. It can be seen from Figure 5 that when the support reaction is less than the friction, the internal and external spline cannot produce a slippage. Here, the bending deflection of input shaft will adapt to the change of position of floating pinion $\left(0\right.$ to $\left.S_{1}\right)$. When the support reaction is greater than the friction, the internal and external spline will produce 
TABLE 1: Gear parameters.

\begin{tabular}{lccccc}
\hline Gear & Teeth $z$ & Pitch diameter $d /(\mathrm{mm})$ & Tooth width $b /(\mathrm{mm})$ & Pressure angle $\alpha /\left(^{\circ}\right)$ & Helical angle $\beta /\left(^{\circ}\right)$ \\
\hline 1 & 32 & 51.1 & 44.5 & 20 & 6 \\
2,3 & 124 & 197.9 & 38.1 & 20 & 6 \\
4,5 & 27 & 68.6 & 66 & 20 & 0 \\
6 & 176 & 447.0 & 59.9 & 20 & 0 \\
\hline
\end{tabular}

a slippage. Here, the slippage will adapt to the change of positions of floating pinion $\left(S_{1}\right.$ to $\left.S_{2}\right)$. However, if the slippage is beyond $S_{2}$, namely, radial clearance between internal and external spline is eliminated, the bending deflection of input shaft will again adapt to the change of position of floating pinion. $S_{1}-S_{2}$ represent the radial clearance between the internal and external spline.

$\Delta F_{x 1}^{(n)}$ and $\Delta F_{y 1}^{(n)}$ represent the support reaction of floating pinion projected on the $x$-axis and $y$-axis, respectively:

$$
\begin{aligned}
& \Delta P_{x 1}^{(n)}=\left\{\begin{array}{c}
-K_{w} \cdot \bar{D} r_{1} \cdot \cos \left(\xi_{1}^{(n)}\right) \\
0 \leq \bar{D} r_{1} \leq S_{1} \\
-F_{m} \cdot \cos \left(\xi_{1}^{(n)}\right) \\
S_{1}<\bar{D} r_{1} \leq S_{2} \\
-\left[F_{m}+K_{w} \cdot\left(\bar{D} r_{1}-S_{2}\right)\right] \cdot \cos \left(\xi_{1}^{(n)}\right) \\
\bar{D} r_{1}>S_{2},
\end{array}\right. \\
& \Delta P_{y 1}^{(n)}=\left\{\begin{array}{c}
-K_{w} \cdot \bar{D} r_{1} \cdot \sin \left(\xi_{1}^{(n)}\right) \\
0 \leq \bar{D} r_{1} \leq S_{1} \\
-F_{m} \cdot \sin \left(\xi_{1}^{(n)}\right) \\
S_{1}<\bar{D} r_{1} \leq S_{2} \\
-\left[F_{m}+K_{w} \cdot\left(\bar{D} r_{1}-S_{2}\right)\right] \cdot \sin \left(\xi_{1}^{(n)}\right) \\
\bar{D} r_{1}>S_{2} .
\end{array}\right.
\end{aligned}
$$

Here, $K_{w}$ is the flexural rigidity of spline shaft; $\zeta^{(n)}$ is a direction angle of vector of $\left(x_{1}^{(n)}, y_{1}^{(n)}\right)$.

$\Delta D_{x 1}^{(n)}$ and $\Delta D_{y 1}^{(n)}$ represent the damping force of floating pinion projected on the $x$-axis and $y$-axis, respectively:

$$
\begin{aligned}
& \Delta D_{x 1}^{(n)}=\left\{\begin{array}{l}
-C_{w} \cdot \bar{D} r_{1} \cdot \cos \left(\xi_{1}^{(n)}\right) \\
0 \leq \bar{D} r_{1} \leq S_{1} \\
-C_{F m} \cdot \cos \left(\xi_{1}^{(n)}\right) \\
S_{1}<\bar{D} r_{1} \leq S_{2} \\
-\left[C_{F m}+C_{w} \cdot\left(\bar{D} r_{1}-S_{2}\right)\right] \cdot \cos \left(\xi_{1}^{(n)}\right) \\
\bar{D} r_{1}>S_{2},
\end{array}\right. \\
& \Delta D_{y 1}^{(n)}=\left\{\begin{array}{c}
-C_{w} \cdot \bar{D} r_{1} \cdot \sin \left(\xi_{1}^{(n)}\right) \\
0 \leq \bar{D} r_{1} \leq S_{1} \\
-C_{F m} \cdot \sin \left(\xi_{1}^{(n)}\right) \\
S_{1}<\bar{D} r_{1} \leq S_{2} \\
-\left[C_{F m}+C_{w} \cdot\left(\bar{D} r_{1}-S_{2}\right)\right] \cdot \sin \left(\xi_{1}^{(n)}\right) \\
\bar{D} r_{1}>S_{2} .
\end{array}\right.
\end{aligned}
$$

Here, $C_{w}$ is the damping of spline shaft bending and $C_{F m}$ is frictional damping.
The support equilibrium conditions of floating pinion can be represented by

$$
\begin{aligned}
& M_{1} \ddot{x}_{1}+\left(\Delta P_{x 1}^{(n)}+\Delta D_{x 1}^{(n)}\right)+\left(P_{12}+D_{12}\right) \cos \zeta_{12} \\
& \quad+\left(P_{13}+D_{13}\right) \cos \zeta_{13}=0, \\
& M_{1} \ddot{y}_{1}+\left(\Delta P_{y 1}^{(n)}+\Delta D_{y 1}^{(n)}\right)+\left(P_{12}+D_{12}\right) \sin \zeta_{12} \\
& \quad+\left(P_{13}+D_{13}\right) \sin \zeta_{13}=0, \\
& \quad m_{\mathrm{eq}, 1} \ddot{u}_{1}+\left(P_{12}+D_{12}\right)+\left(P_{13}+D_{13}\right)=0 .
\end{aligned}
$$

Equations (16) will be combined with other dynamics differential equations to establish clearance nonlinear mathematical model. Then, through solving this nonlinear mathematical model, the transmission torque of each gear pair is obtained. Finally, the load-sharing coefficient will be obtained.

\section{Examples}

To verify the correctness of the method proposed in this paper, the initial parameters of the numerical examples will be completely based on the initial data in [8] of the NASA Research Institutions. Finally, the theoretical analysis results proposed in this paper and experimental results of [8] will be compared.

Gear parameters are shown in Table 1. Input power $P=$ $373 \mathrm{Kw}$ and input speed $n_{1}=8780 \mathrm{r} / \mathrm{min}$.

The loaded transmission errors (LTE) of each gear pair of the system related to Table 1 are shown in Figure 6.

Figure 6 shows the load transmission error (LTE) of different meshing positions on the tooth face. Figure 6(a) is the LTE of level I helical gear pairs. Here, the LTE fluctuation is $(-7.21 \sim 0.12) /^{\prime \prime}$. Figure $6(\mathrm{~b})$ is the LTE of level II gear pair. Here, the LTE fluctuation is $(-11.5 \sim 0.11) /^{\prime \prime}$. Considering the above analysis, the range of fluctuation of the spur gear pairs LTE is larger than the one of the helical gear pairs.

The time-varying mesh stiffness incentive of each gear pair abased on the LTCA is shown in Figure 7; meanwhile, the time-varying mesh stiffness incentive based on the empirical formula (IS06336.1996) [19] is shown.

Figure 7 shows the mechanical properties of different meshing positions on the tooth face. Figure 7(a) is the timevarying mesh stiffness incentive of the first-stage gear pair. Here, the meshing stiffness fluctuation is $\left(7.29 \times 10^{5} \sim 1.17 \times\right.$ $\left.10^{6}\right) / \mathrm{N} \cdot \mathrm{mm}^{-1}$. Figure $7(\mathrm{~b})$ is the time-varying mesh stiffness incentive of the second-stage gear pair. Here, the meshing stiffness fluctuation is $\left(1.09 \times 10^{5} \sim 1.27 \times 10^{6}\right) / \mathrm{N} \cdot \mathrm{mm}^{-1}$. 
TABLE 2: The natural frequency analysis results.

\begin{tabular}{lccccccccc}
\hline Order & $\begin{array}{c}\text { Natural } \\
\text { frequency }\end{array}$ & Order & $\begin{array}{c}\text { Natural } \\
\text { frequency }\end{array}$ & Order & $\begin{array}{c}\text { Natural } \\
\text { frequency }\end{array}$ & Order & $\begin{array}{c}\text { Natural } \\
\text { frequency }\end{array}$ & $\begin{array}{c}\text { Order } \\
\text { frequency }\end{array}$ \\
\hline 1 & 0 & 7 & 199.877 & 13 & 468.116 & 19 & 1018.471 & 25 & 2084.417 \\
2 & 142.802 & 8 & 273.048 & 14 & 523.136 & 20 & 1018.471 & 26 & 2084.418 \\
3 & 152.281 & 9 & 322.915 & 15 & 824.536 & 21 & 1748.084 & 27 & 3774.596 \\
4 & 153.447 & 10 & 354.337 & 16 & 824.536 & 22 & 1794.751 & 28 & 3774.596 \\
5 & 191.011 & 11 & 386.456 & 17 & 824.544 & 23 & 2084.417 & 29 & 11694.802 \\
6 & 191.011 & 12 & 387.002 & 18 & 824.550 & 24 & 2084.417 & 30 & 11694.802 \\
\hline
\end{tabular}

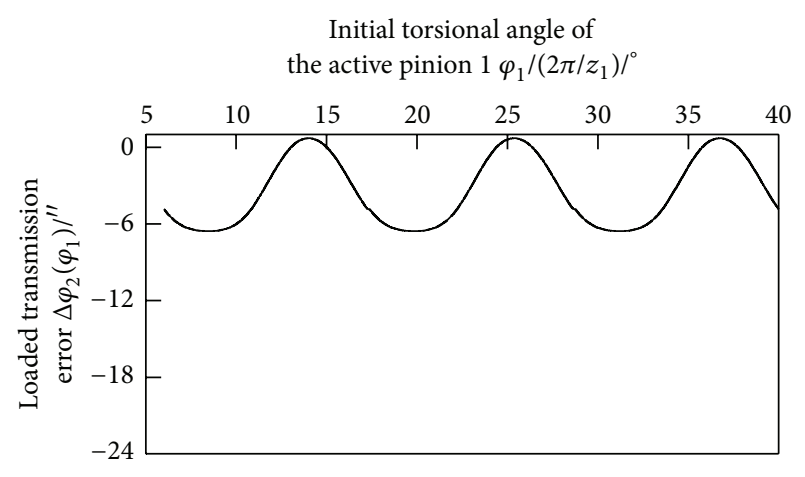

(a)

Initial torsional angle of

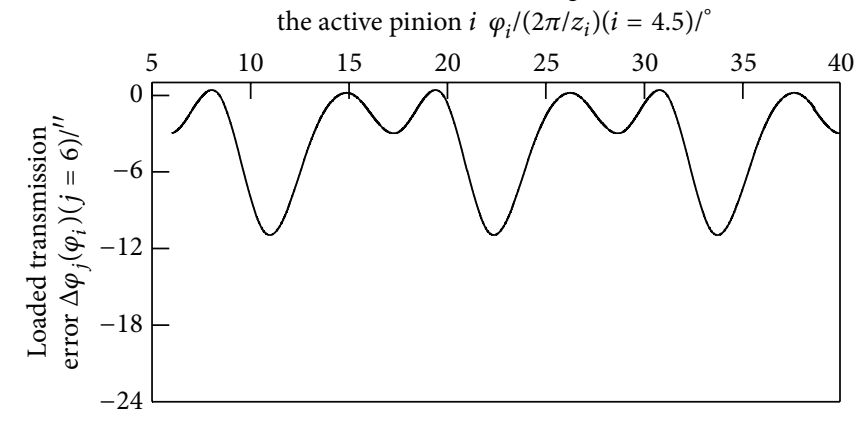

(b)

FIGURE 6: Transmission errors. Illustration of (a) I-stage helical gear pairs and (b) II-stage spur gear pairs.

Differential equation is expressed in formula of $[M]\left\{X^{\prime \prime}\right\}+[C]\left\{X^{\prime}\right\}+([K(t)]-e(t))\{X\}=\left\{P_{0}\right\}$. The natural characteristics of problem can be converted into solving the equations of $\omega_{i}^{2}[M]=[\bar{K}],[M]$ is system mass matrix, $[\bar{K}]$ is stiffness matrix, and the time-varying meshing stiffness is replaced with average mesh stiffness. 30 order natural frequency results are calculated and shown in Table 2.

As seen from Table 2, the fundamental frequency of system is $142.802 \mathrm{~Hz}$. Then, due to the symmetric structure of dual power-split transmission system, the natural frequency of the equal value appeared. Due to the complexity and particularity of the system, the quadruple frequency phenomenon appeared.

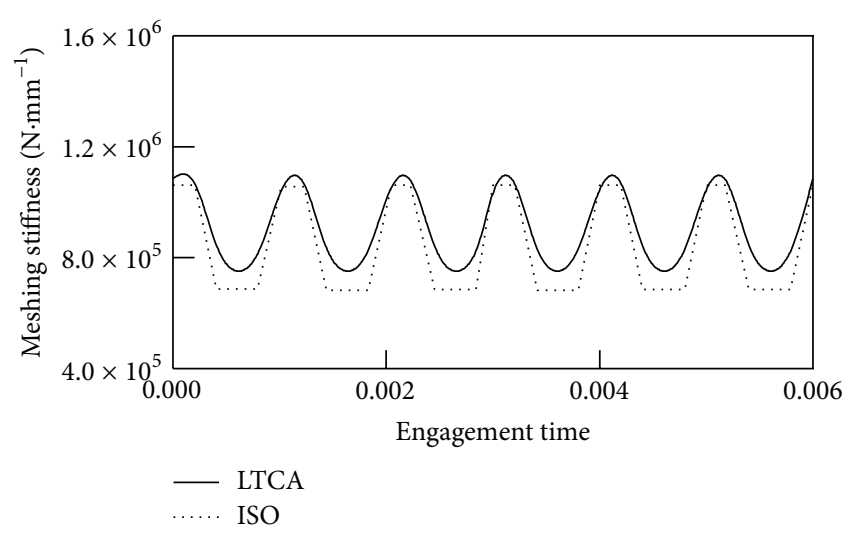

(a)

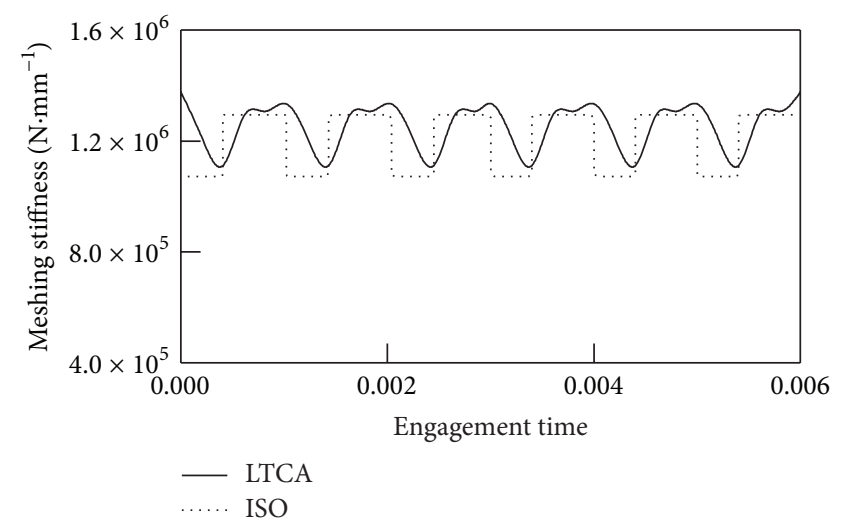

(b)

Figure 7: The curves of time-varying mesh stiffness incentive. Illustration of (a) level-I helical gear pairs and (b) level-II spur gear pairs.

The natural frequency corresponding to the various degrees of freedom vibration model is shown in Figure 8. It can be seen from the vibration mode curve, the node between 23 and 29 of the fundamental frequency is the largest relative amplitude.

From the above analysis, the torsional-vibration natural frequency of transmission system has a reasonable distribution. Meanwhile, it can meet the requirements of design.

The dynamic load reflects the vibration amplitude. Figure 9 is time-history dynamic load and FFT spectrum diagram of the gears at all levels of system. 

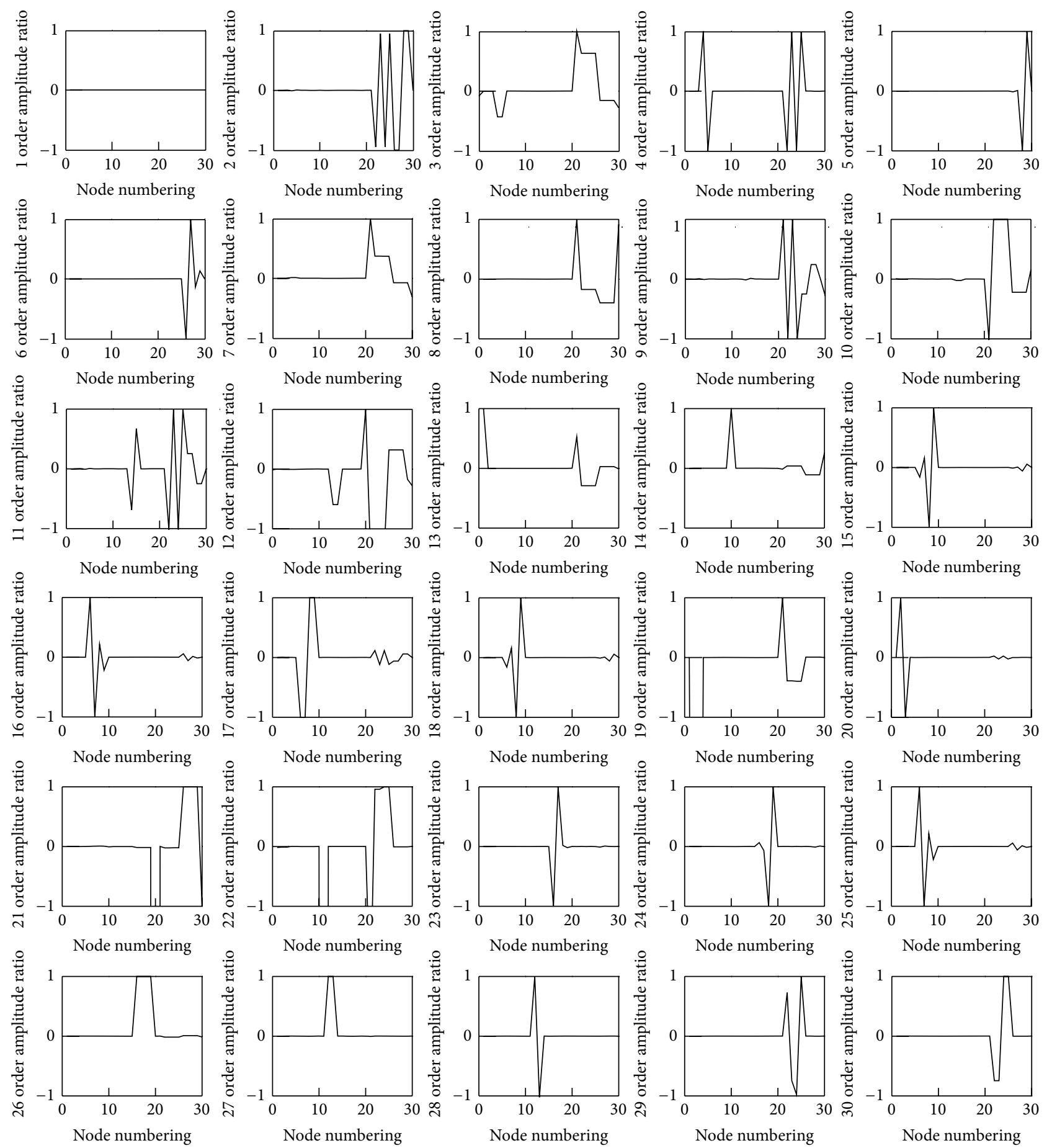

FIGURE 8: Each natural principal mode of system.

It can be seen from Figure 9 that level I of meshing frequency is $4682.67 \mathrm{~Hz}$ and level II of meshing frequency is $1019.13 \mathrm{~Hz}$. After a certain calculation, dynamic load coefficient of the gear pair at all levels of system is obtained in the standard condition without errors, respectively, which is 1.152 and 1.065. At the same time, it can be seen that a strong vibration of the whole system happened in meshing frequency of the gear pair.
Vibration acceleration reflects the impact force. The system vibration acceleration time history is shown in Figure 10 with the standard conditions.

It can be seen from Figure 10 that the vibration acceleration RMS $\left(\mathrm{m} / \mathrm{s}^{2}\right)$ of the gear pair at all levels of system is 4.989 and 2.163 , respectively. It can be seen that a strong vibration of the vibration acceleration happened in meshing frequency of the gear pair at all levels. 

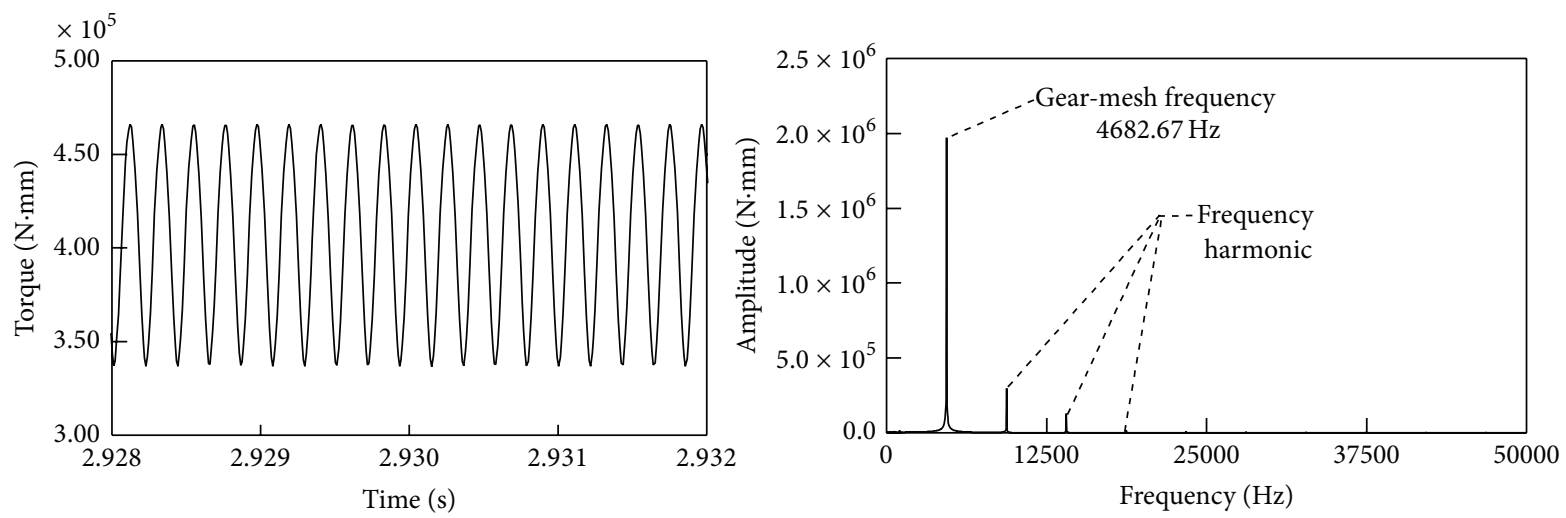

(a) The I-stage dynamic load and the corresponding FFT spectrum
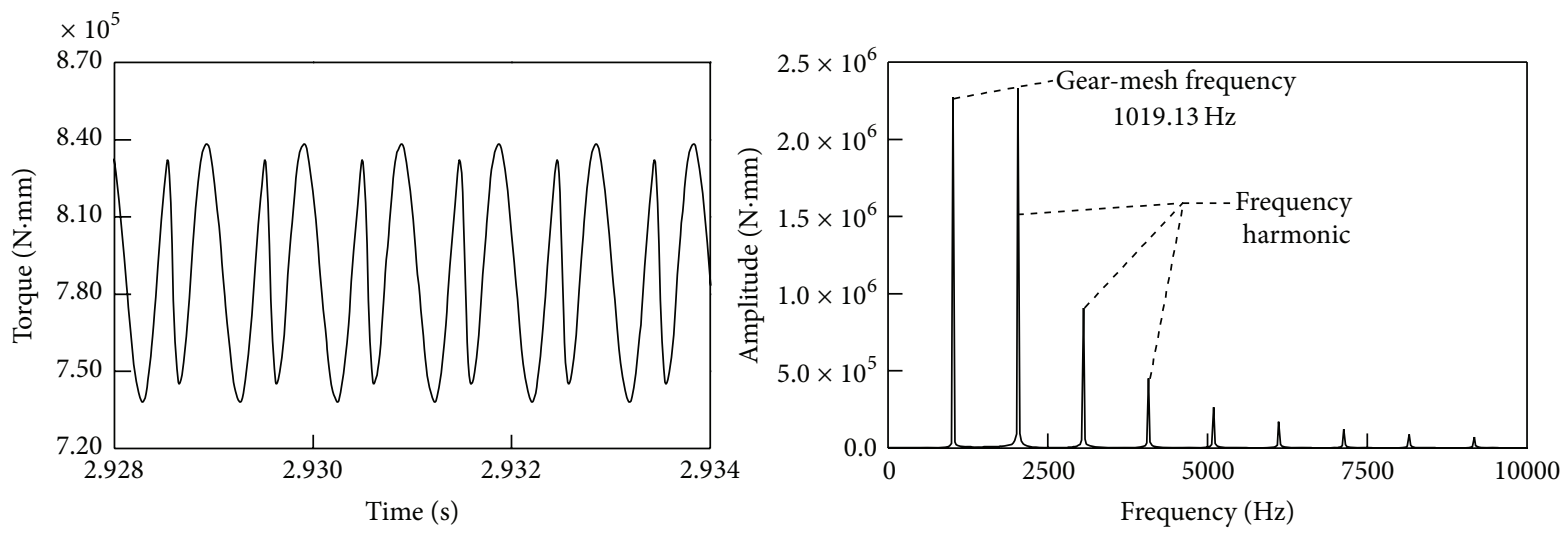

(b) Level II dynamic load and the corresponding FFT spectrum diagram

FIGURE 9: Dynamic load time history and FFT spectrum under standard conditions.

When the input speed was given $4390 \mathrm{r} / \mathrm{min}$, the vibration acceleration and FFT spectrum of the II grade gear pair are shown in Figure 11.

It can be seen from Figure 11 that when the input speed is reduced to $4390 \mathrm{r} / \mathrm{min}$, the vibration acceleration RMS is 1.290 and 1.290 , respectively. Here, the biggest vibration amplitude is in the fourth harmonic.

With the change of rotating speed, dynamic load coefficient is shown in Figure 12; here, $\xi_{g}$ is meshing damping ratio.

It can be seen from Figure 12 that the dynamic load coefficient is changed with the change of rotating speed. By the above analysis of system dynamic characteristic, transmission system must stay away from the resonance speed according to the reasonable working speed requirements. With the increase of damping ratio, the dynamic load of near critical speed can be reduced.

The center distance installation errors influence the loadsharing characteristics of transmission system. Such as when $\Delta A_{x 2}=\Delta A_{x 4}=\Delta A_{x 6}=0.05 \mathrm{~mm}$ is given, the loadsharing coefficient is 1.0983. If these errors individually affect the load-sharing characteristics of transmission system, the result is shown in Figure 13.

Figure 13 shows that the torque is cyclically fluctuating at each meshing position in different errors of $\Delta A_{x 2}, \Delta A_{x 4}$, and $\Delta A_{x 6}$, which reflect the load distribution at different engagement position in the tooth surface. With the influence of $\Delta A_{x 2}, \Delta A_{x 4}$, and $\Delta A_{x 6}$, the load-sharing coefficient is, respectively, 1.0207, 1.0783, and 1.0641.

Load-sharing coefficient with a single influence of the center distance installation error is shown in Figure 14.

Figure 14 shows that level II pinion plays a vital role in the load-sharing coefficient. Thus, in the process of the system installation, level II pinion errors should be mainly considered.

The influence of the floating pinion based on spline clearance floating is shown in Figure 15.

Figure 15 shows that load-sharing coefficient is 1.0307 , 1.0133 , and 1.0044 under the influence of the spline clearance.

Under the different error conditions, the curves of loadsharing coefficient changed with the spline clearance are shown in Figure 16.

It can be seen from Figure 16 that the load-sharing coefficient is decreased with the increase of spline clearance. In other words, load-sharing performance of system will be better.

\section{Dynamics Model Validation}

In this section, the theoretical calculation based on the method proposed in this paper and the analysis results of 

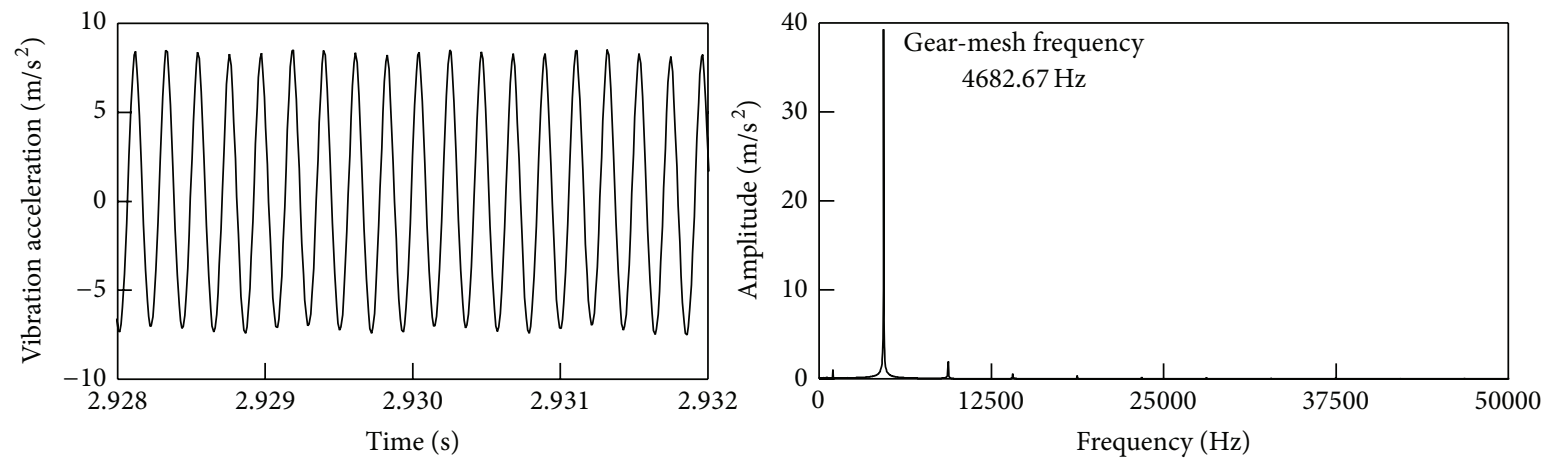

(a) Level I acceleration and the corresponding FFT spectrum
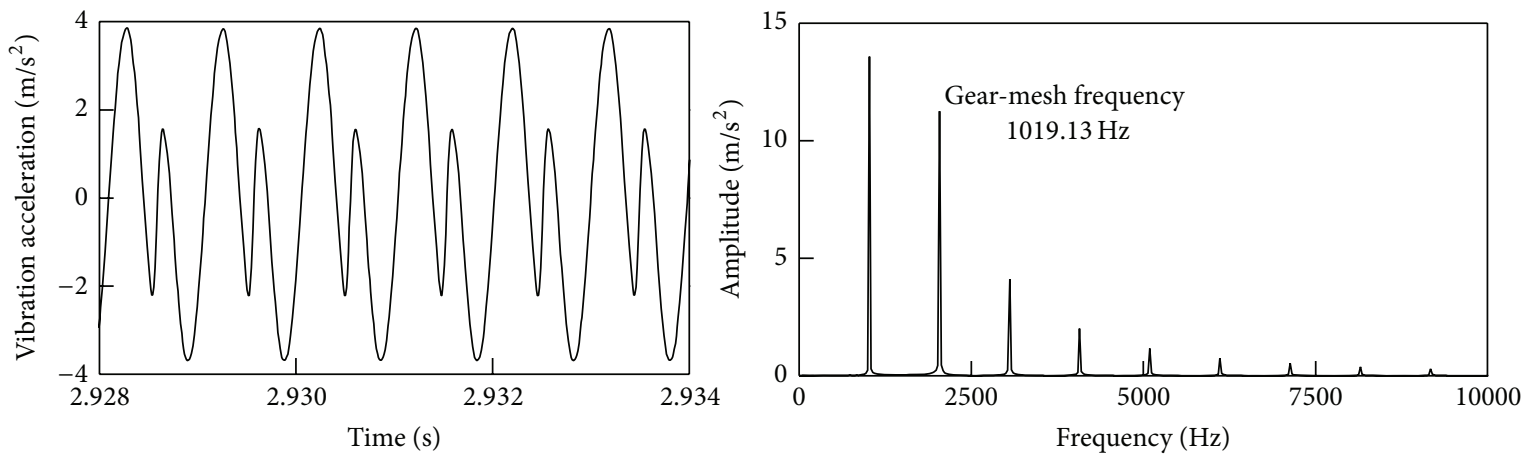

(b) Level II acceleration and the corresponding FFT spectrum

FIGURE 10: Vibration acceleration time history and FFT spectrum under standard conditions.
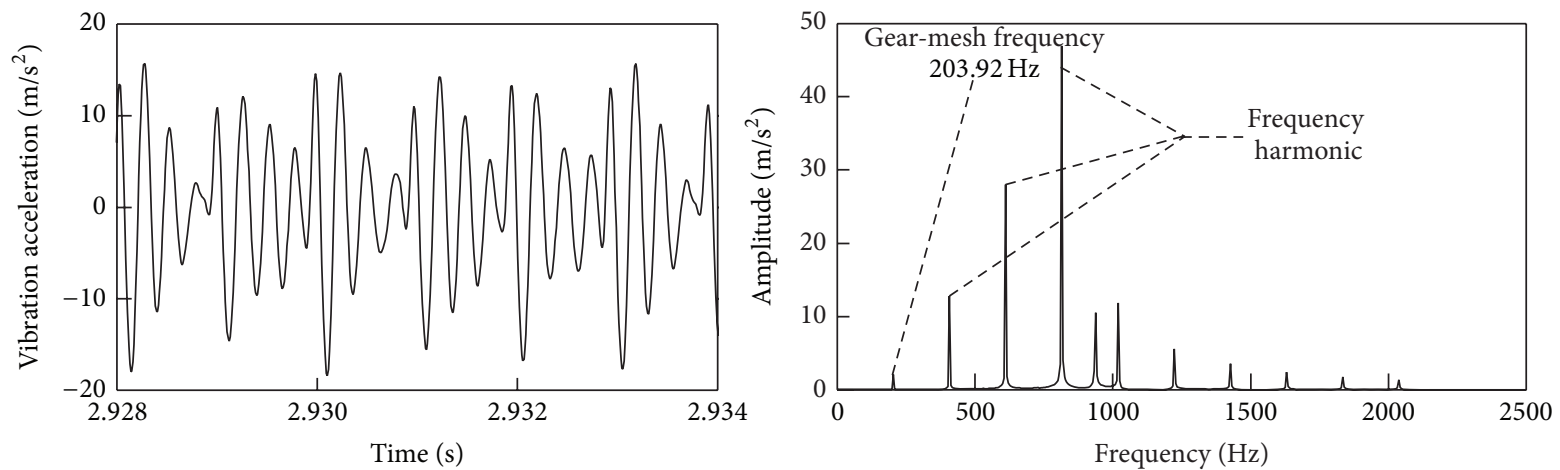

FIGURE 11: II-stage time-history vibration acceleration and FFT spectrum.

[8] will be compared. Dual power-split transmission system mentioned in [8] is a power transmission device used in aviation helicopters. Experimental equipment of dual powersplit transmission system is given in [8]; this is shown in Figure 17(a). Dual power-split transmission device is composed of a power flow of closed loop system. The principle of system is shown in Figure 17(b).

Theoretical analysis results of the time-history dynamic load of the gear pair at all levels of system are compared with the calculation results of [8]. Then, the results are shown in Figure 18. Here, the condition is the standard no errors conditions; the data is the time domain steady state response data. At the same time, in the process of transmission torque, the static loads of the various gears are given, respectively, which are $4.05 \times 10^{5} \mathrm{~N} \cdot \mathrm{mm}, 7.86 \times 10^{5} \mathrm{~N} \cdot \mathrm{mm}$, and 1.02 $\times 10^{7} \mathrm{~N} \cdot \mathrm{mm}$. In order to make a better comparison, the unit of inch-pounds (in.-lb) of [8] was transformed to the $\mathrm{N} \cdot \mathrm{mm}$

It can be seen from Figure 18(a) that dynamic load of level I gear pair is fluctuated $4.05 \times 10^{5} \mathrm{~N} \cdot \mathrm{mm}$ from [8]. Figure 18(b) shows that the dynamic load of level I gear pair is fluctuated $4.11 \times 10^{5} \mathrm{~N} \cdot \mathrm{mm}$ from theoretical calculation 


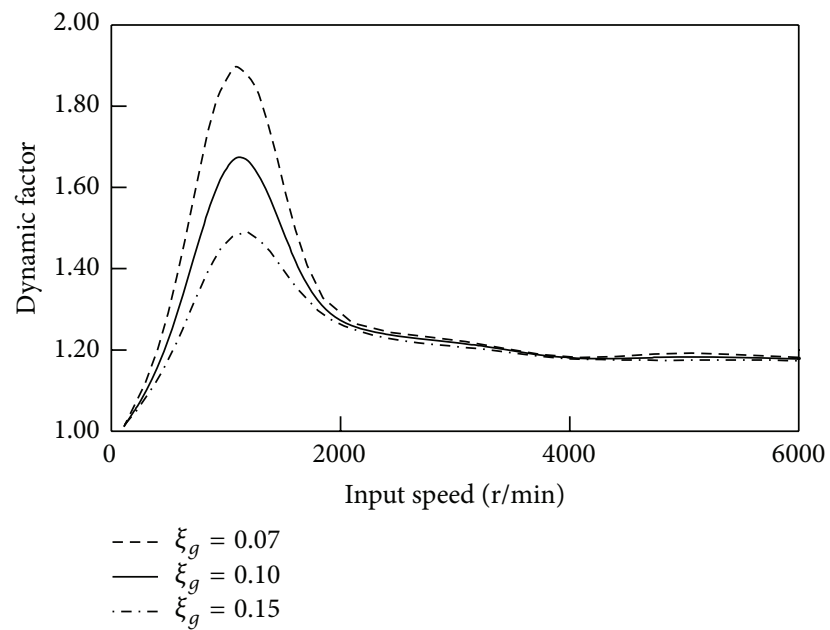

(a) Level I dynamic load coefficient

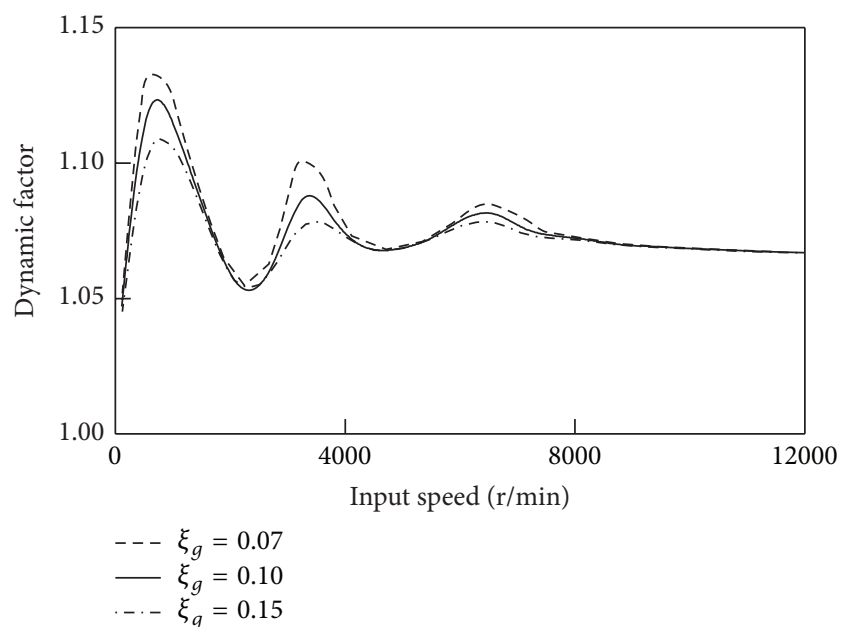

(b) Level II dynamic load coefficient

FIGURE 12: The relationship between the dynamic factor and speed.

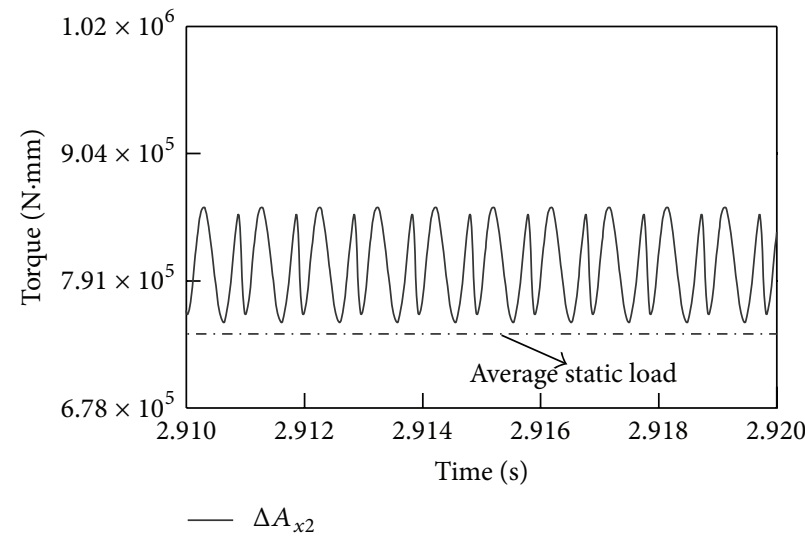

(a) Gear 2 error of $\Delta A_{x 2}$

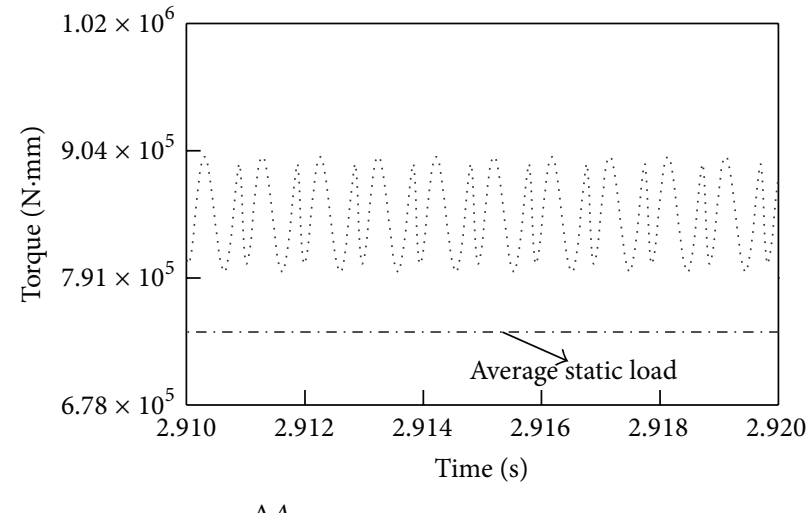

(b) Gear 4 error of $\Delta A_{x 4}$

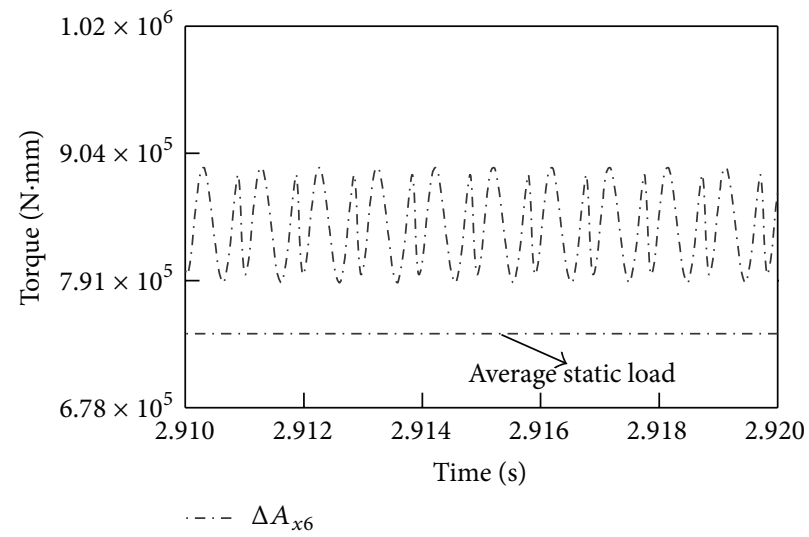

(c) Gear 6 error of $\Delta A_{x 6}$

FIGURE 13: Load-sharing characteristics changed with installation error. 


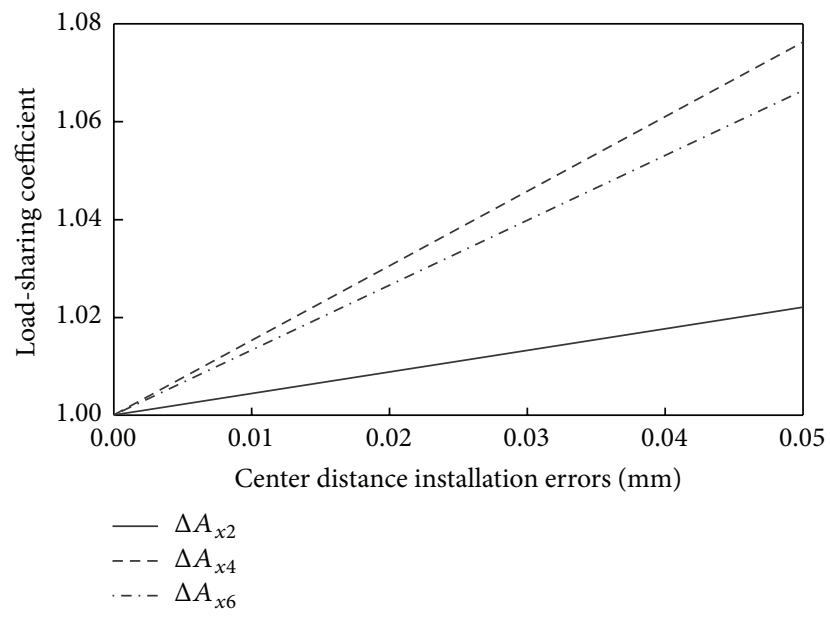

FIGURE 14: Load-sharing coefficient curves with the change of installation errors.

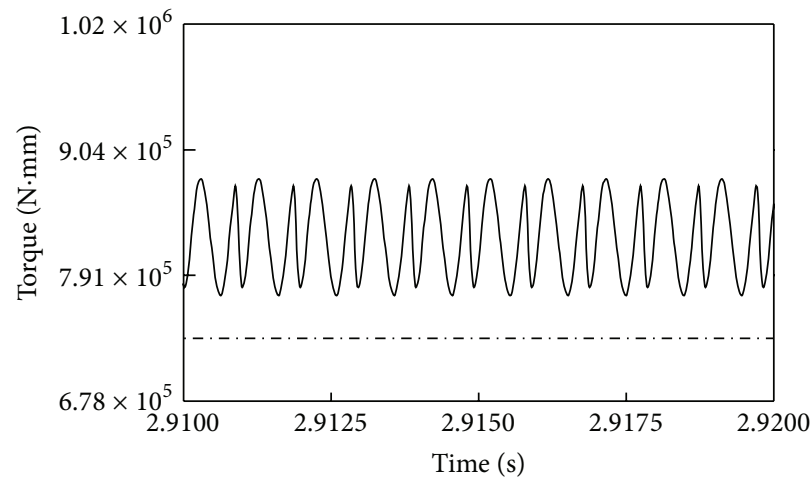

(a) Spline clearance is $0 \mathrm{~mm}$

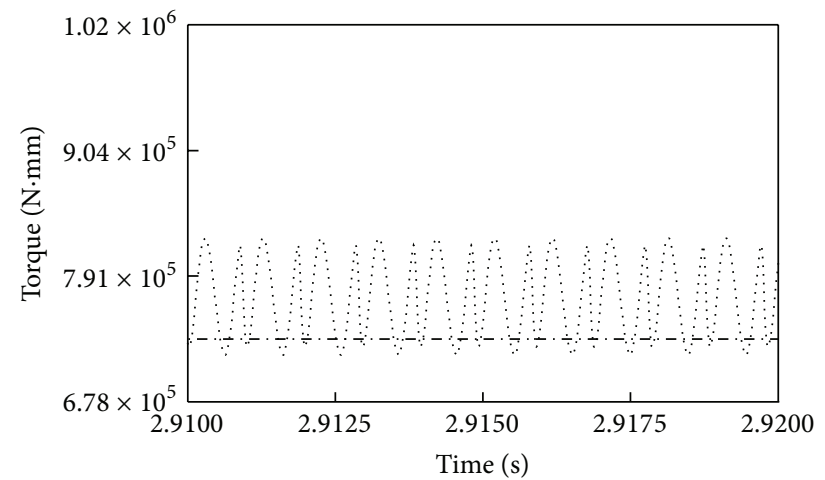

(b) Spline clearance is $0.85 \mathrm{~mm}$

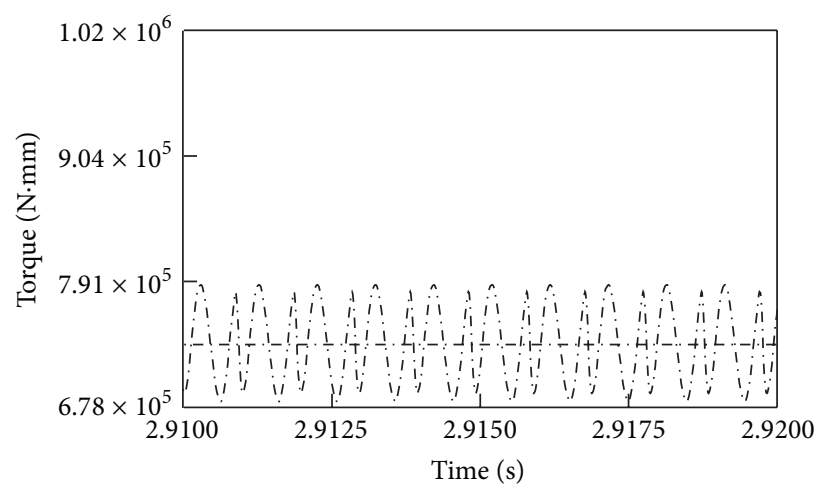

(c) Spline clearance is $1.231 \mathrm{~mm}$

FIGURE 15: Dynamic load under the influence of the spline clearance.

and analysis. Here, dynamic load coefficient is 1.152 and 1.117, respectively. It can be seen from Figure 18(c) that dynamic load of level II gear pair is fluctuated $7.86 \times 10^{5} \mathrm{~N} \cdot \mathrm{mm}$ from [8]. Figure 18(d) shows that the dynamic load of level II gear pair is fluctuated $7.92 \times 10^{5} \mathrm{~N} \cdot \mathrm{mm}$ from theoretical calculation and analysis. Here, dynamic load coefficient is 1.065 and 1.112, respectively. It can be seen from Figure 18(e) that dynamic load of level III gear pair is fluctuated
$1.02 \times 10^{6} \mathrm{~N} \cdot \mathrm{mm}$ from [8]. Figure $18(\mathrm{f})$ shows that the dynamic load of level III gear pair is fluctuated $1.14 \times 10^{6} \mathrm{~N} \cdot \mathrm{mm}$ from theoretical calculation and analysis. Here, dynamic load coefficient is 1.062 and 1.077, respectively. Through the above analysis, the theoretical analysis and the calculation data of [8] are consistent. The dynamic load coefficient is also consistent. It is effective to prove the feasibility of dynamic calculation method proposed in this paper. 


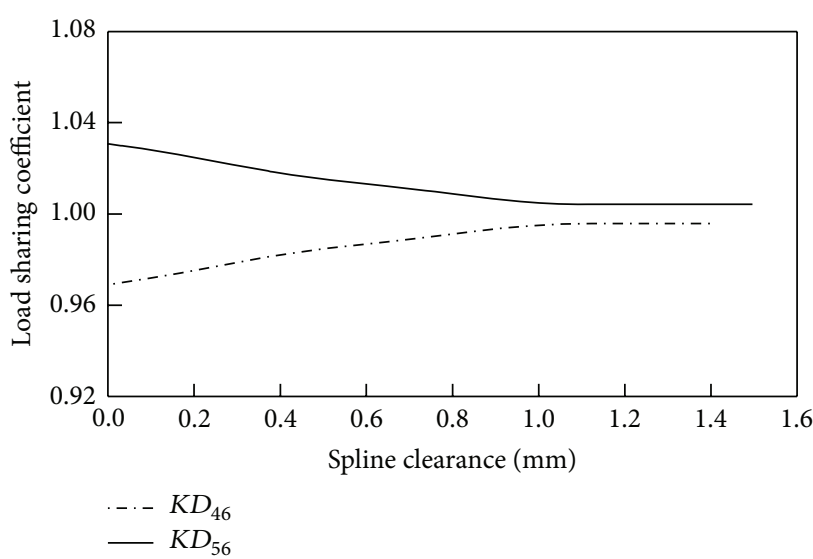

(a) Clearance floating coefficient changes with $\Delta A_{x 2}$

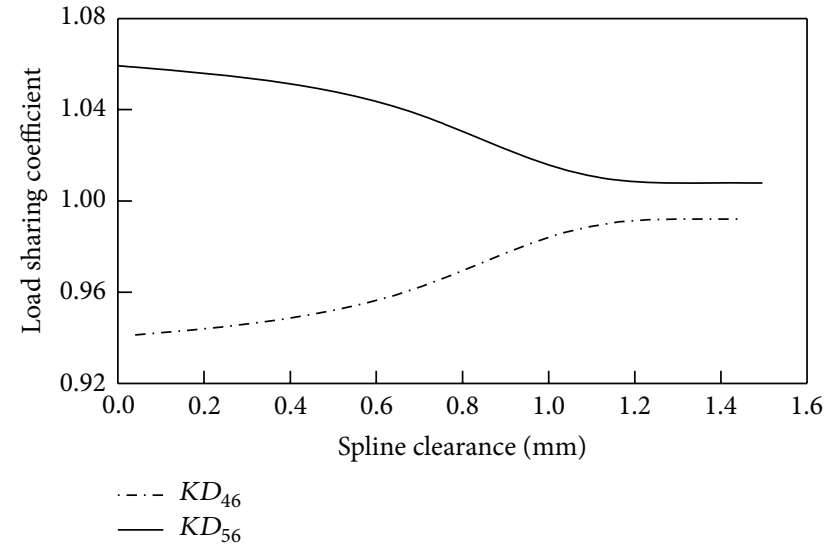

(b) Clearance floating coefficient changes with $\Delta A_{x 4}$

FIGURE 16: Load-sharing coefficient changed with spline clearance.

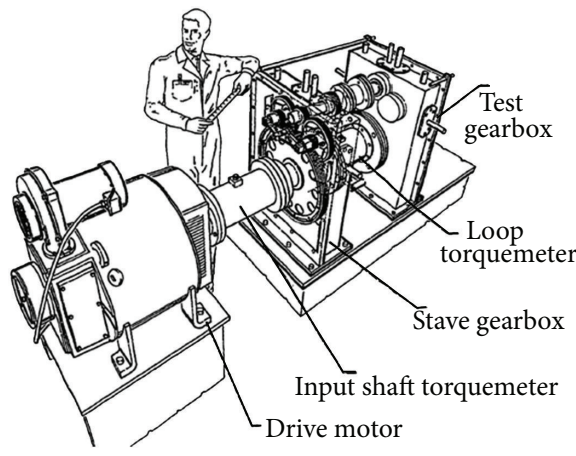

(a) Experimental split torque gearbox test facility

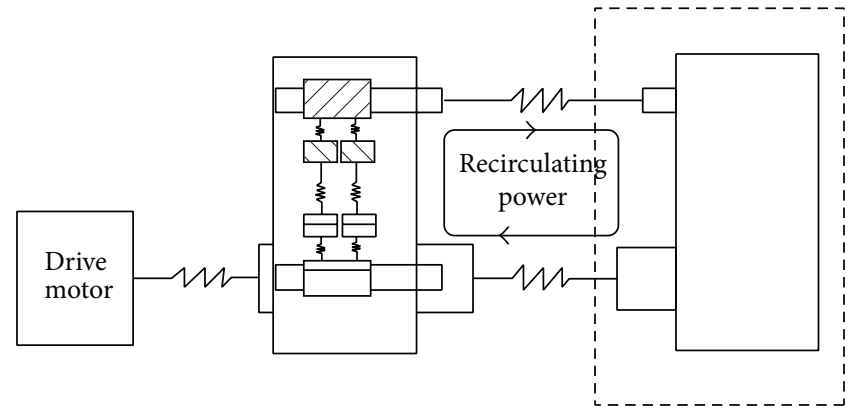

Test gearbox

(b) Power closed circuit principle diagram

FIGURE 17: Experimental equipment and the principle diagram.

Figure 19(a) is the FFT spectrum of level II gear pair dynamic load from [8]; Figure 19(b) is the FFT spectrum of level II gear dynamic load from the theoretical analysis.

It can be seen from Figure 19(a) that the meshing fundamental frequency is $1034.67 \mathrm{~Hz}$ from [8]. Figure 19(b) shows that the meshing fundamental frequency is $1019.13 \mathrm{~Hz}$ from theoretical calculation and analysis. Through the above analysis, trend of the theoretical analysis and the calculation data of [8] are consistent.

The influence of installation error $(0.0040 \mathrm{in}$. $(0.1016 \mathrm{~mm}))$ is considered in [8]. The results of two branches of time-history dynamic load are shown in Figure 20(a). Then, by using the calculation method proposed in this paper, the theoretical calculation results are given in Figure 20(b).

The power allocation is, respectively, $56.59 \%$ and $55.91 \%$ with the analysis of [8] and theoretical analysis in this paper. The loading-sharing coefficient is, namely, 1.132 and 1.118. The results of [8] and theoretical analysis are consistent.

The equivalent average meshing stiffness is adopted in [8], and it cannot reflect the real tooth surface meshing process. The mathematical model putted forward in this paper is based on the tooth contact analysis (TCA) and load tooth contact analysis (LTCA). This method can be dispersed in the whole meshing process of each gear pair to limited meshing point. Each meshing position will be analyzed by the mechanical properties.

Time-varying mesh stiffness using the above analysis method has a higher accuracy than the traditional stiffness excitation using average mesh stiffness. This mesh stiffness more accurately reflects the dynamic characteristics of the whole system. Mathematical model of dual power-split transmission system proposed in this paper will have some theoretical value; at the same time, this mathematical model could be applied in the planetary and star gear transmission system.

\section{Conclusions}

Through the analysis and comparison, we can get the following main conclusions.

(1) It can get more accurate mesh stiffness using TCA and LTCA technology. The dynamic model is established 


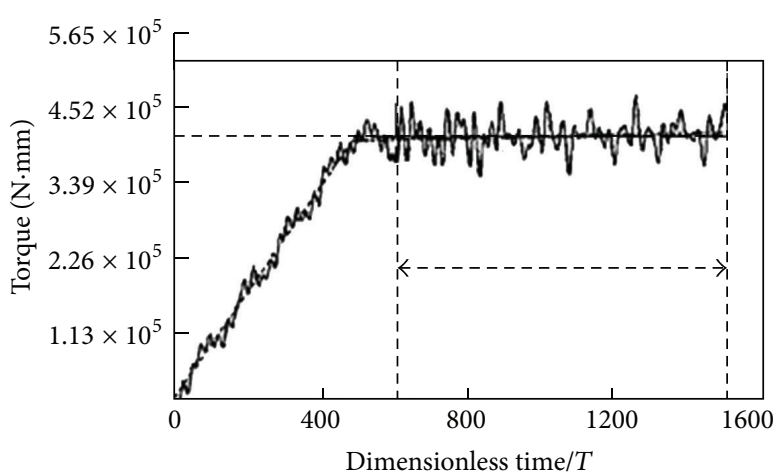

(a) Level I dynamic load from [8] analysis

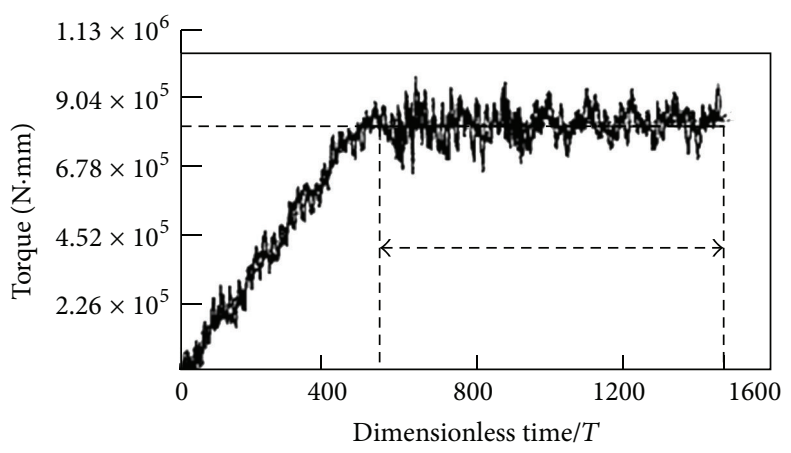

(c) Level II dynamic load from [8] analysis

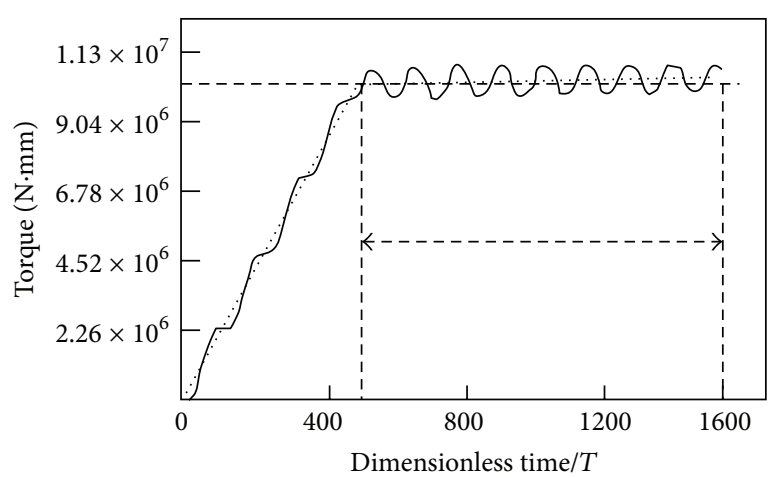

(e) Level III dynamic load from [8] analysis

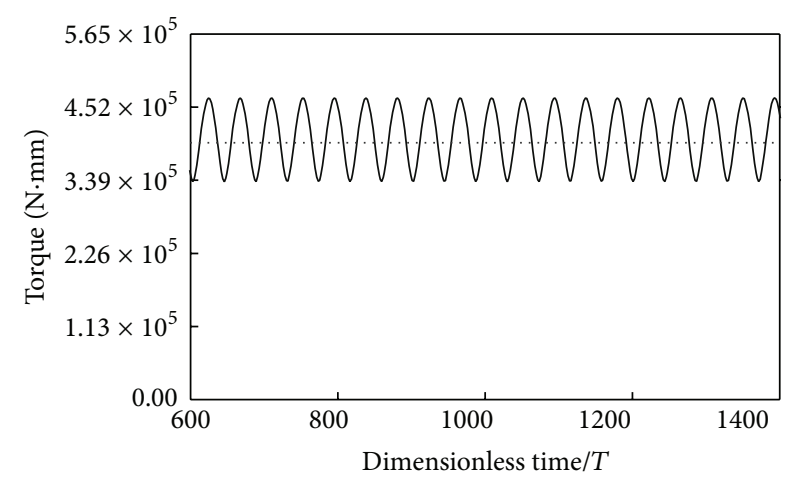

(b) Level I dynamic load from the theory analysis

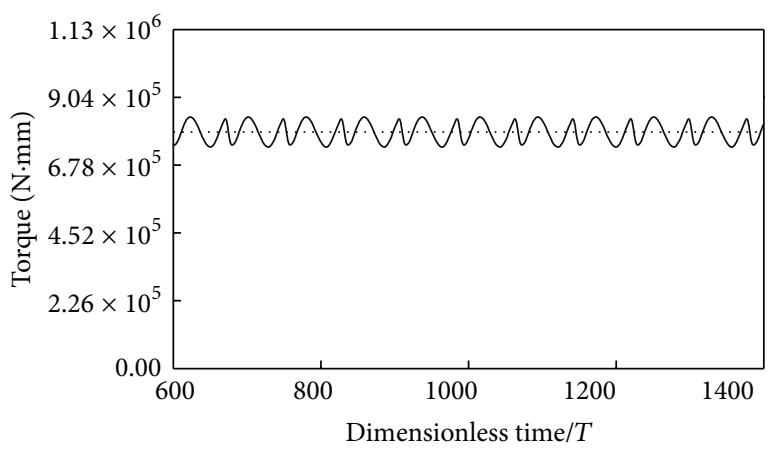

(d) Level II dynamic load from the theory analysis

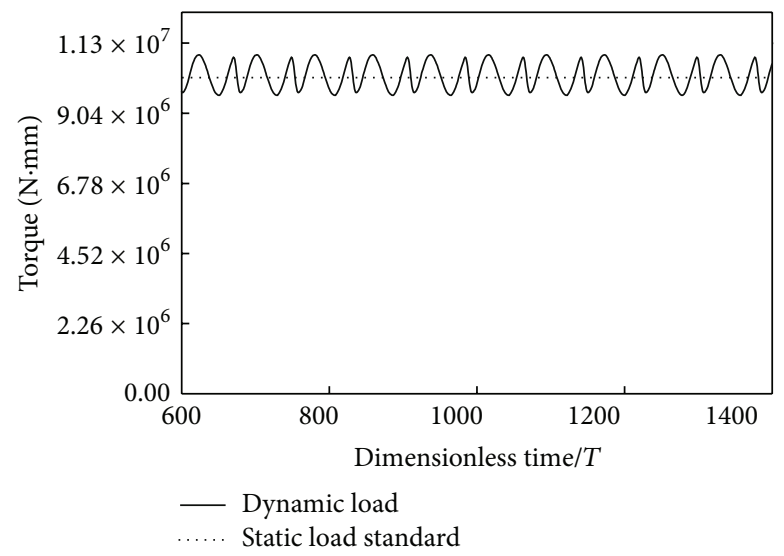

(f) Level III dynamic load from the theory analysis

FIGURE 18: Contrast between theory analysis and [8] calculation of dynamic load.

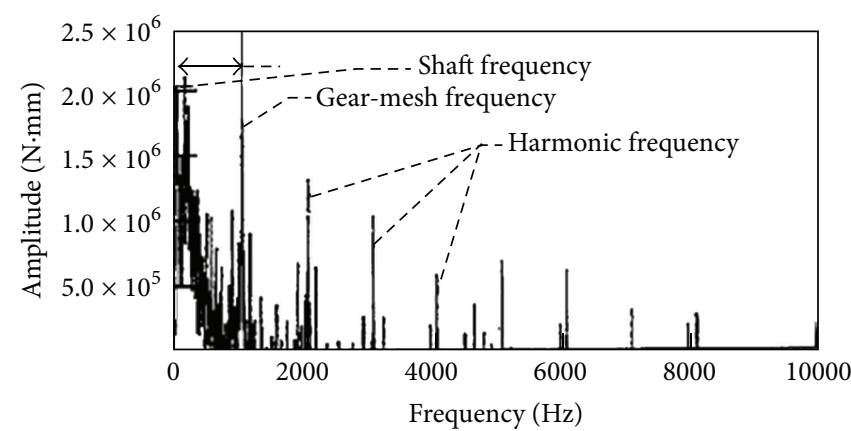

(a) FFT spectrum diagram from [8] analysis

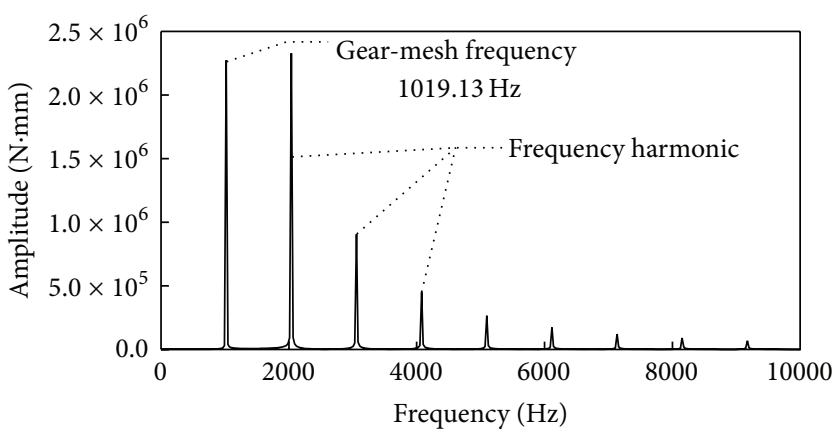

(b) FFT spectrum diagram from the theory analysis

FIGURE 19: FFT spectrum of dynamic load contrast between theory analysis and [8] calculation. 


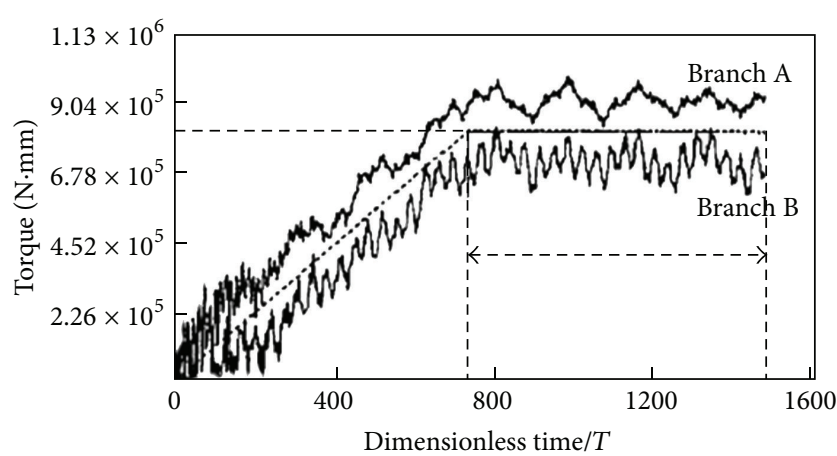

(a) Dynamic load from [8] analysis

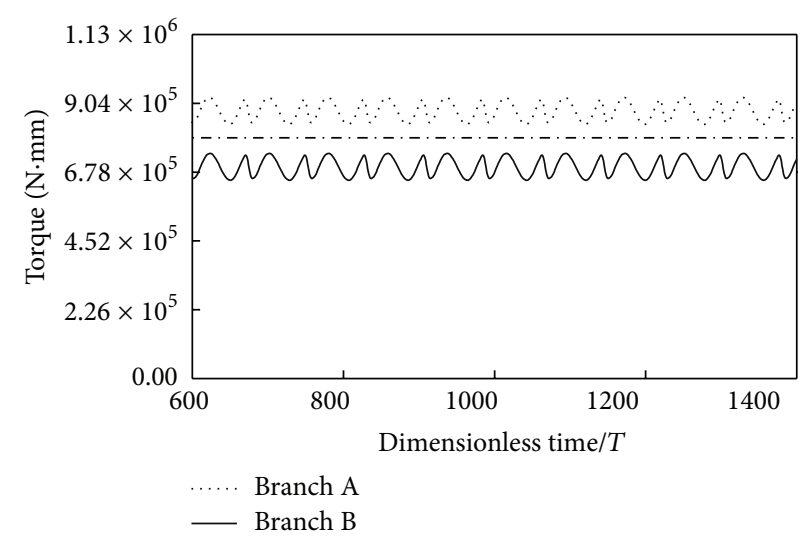

(b) Dynamic load from the theory analysis

FIGURE 20: Contrast between theory analysis and [8] calculation of dynamic load with installation errors.

through an effective integration of power-split transmission system.

(2) Time-varying mesh stiffness based on LTCA was analyzed by using the Fourier series transfer; the periodic function was used to improve the calculation accuracy. The dynamics model of power-split transmission system can provide a basis for solving and analyzing the dynamic design.

(3) The installation errors accumulatively influence the load-sharing characteristics. The installation errors of level II components should be paid more attention. The floating pinion can effectively improve the loadsharing characteristics of system. The quantity of spline clearance should not be excessive. Too much clearance will lead the system to produce serious vibration and shock.

\section{Conflict of Interests}

The authors declare that there is no conflict of interests regarding the publication of this paper.

\section{Acknowledgments}

The authors would like to acknowledge the support provided to the project by the National Natural Science Foundation of China (51375384) and the Research Foundation of Education Bureau of Shaanxi Province, China (12jk0692).

\section{References}

[1] A. Kahraman, A. A. Kharazi, and M. Umrani, "A deformable body dynamic analysis of planetary gears with thin rims," Journal of Sound and Vibration, vol. 262, no. 3, pp. 752-768, 2003.

[2] W. Bartelmus and R. Zimroz, "Vibration condition monitoring of planetary gearbox under varying external load," Mechanical Systems and Signal Processing, vol. 23, no. 1, pp. 246-257, 2009.
[3] V. K. Ambarisha and R. G. Parker, "Nonlinear dynamics of planetary gears using analytical and finite element models," Journal of Sound and Vibration, vol. 302, no. 3, pp. 577-595, 2007.

[4] D. R. Kiracofe and R. G. Parker, "Structured vibration modes of general compound planetary gear systems," Journal of Vibration and Acoustics, Transactions of the ASME, vol. 129, no. 1, pp. 1-16, 2007.

[5] J. G. Kish, "Sikorsky aircraft advanced rotorcraft transmission (art) program-final report," NASA CR-191079, NASA Lewis Research Center, Cleveland, Ohio, USA, 1993.

[6] J. G. Kish, "Comanche drive system," in Proceedings of the Rotary Wing Propulsion Specialists' Meeting, American Helicopter Society, Williamsburg, Va, USA, 1993.

[7] T. L. Krantz, "A method to analyze and optimize load sharing of split path transmission," Tech. Rep. NASA TM-107201, NASA Lewis Research Center, Cleveland, Ohio, USA, 1996.

[8] T. L. Krantz, "Dynamic of a split torque helicopter transmission," NASA TM-106410, NASA Lewis Research Center, Cleveland, Ohio, USA, 1994.

[9] Z. Fang, Y. Shen, and Z. Huang, "The dynamic behaviour of star gearing with three branches," Journal of Aerospace, vol. 17, no. 7, pp. 341-350, 1990.

[10] Y. Guo, J. Keller, and R. G. Parker, "Nonlinear dynamics and stability of wind turbine planetary gear sets under gravity effects," European Journal of Mechanics, vol. 47, pp. 45-57, 2014.

[11] S.-J. Tsai, G.-L. Huang, and S.-Y. Ye, "Gear meshing analysis of planetary gear sets with a floating sun gear," Mechanism and Machine Theory, vol. 22, no. 1, pp. 1-19, 2014.

[12] B. Boguski, A. Kahraman, and T. Nishino, "A new method to measure planet load sharing and sun gear radial orbit of planetary gear sets," Transactions of the ASME, Journal of Mechanical Design, vol. 3, no. 7, pp. 1-10, 2012.

[13] P. Sondkar and A. Kahraman, "A dynamic model of a doublehelical planetary gear set," Mechanism and Machine Theory, vol. 70, pp. 157-174, 2013.

[14] M. R. Kang and A. Kahraman, "Measurement of vibratory motions of gears supported by compliant shafts," Mechanical Systems and Signal Processing, vol. 29, pp. 391-403, 2012.

[15] A. Kahraman, "Load sharing characteristics of planetary transmissions," Mechanism and Machine Theory, vol. 29, no. 8, pp. 1151-1165, 1994. 
[16] A. Kahraman, "Planetary gear train dynamics," Journal of Mechanical Design, Transactions of the ASME, vol.116, no. 3, pp. 713-720, 1994.

[17] A. Kahraman, A. A. Kharazi, and M. Umrani, "A deformable body dynamic analysis of planetary gears with thin rims," Journal of Sound and Vibration, vol. 262, no. 3, pp. 752-768, 2003.

[18] R. G. Parker and J. Lin, "Mesh phasing relationships in planetary and epicyclic gears," Journal of Mechanical Design, vol. 126, no. 2, pp. 365-370, 2004.

[19] Z.-D. Fang, "Loaded tooth contact analysis of modified helical gears," Journal of Aerospace Power, vol. 12, no. 3, pp. 251-254, 329, 1997.

[20] L. Litvin F, Gear Geometry and Applied Theory, PTR Prentice Hall, Englewood Cliffs, NJ, USA, 1994. 

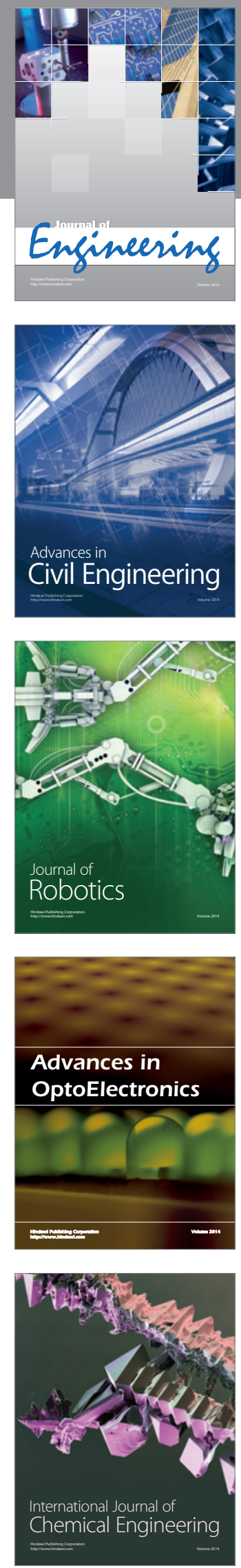

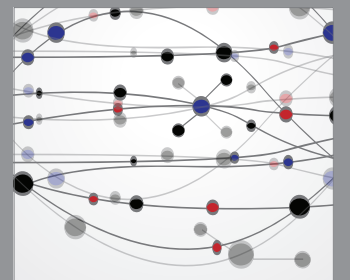

The Scientific World Journal
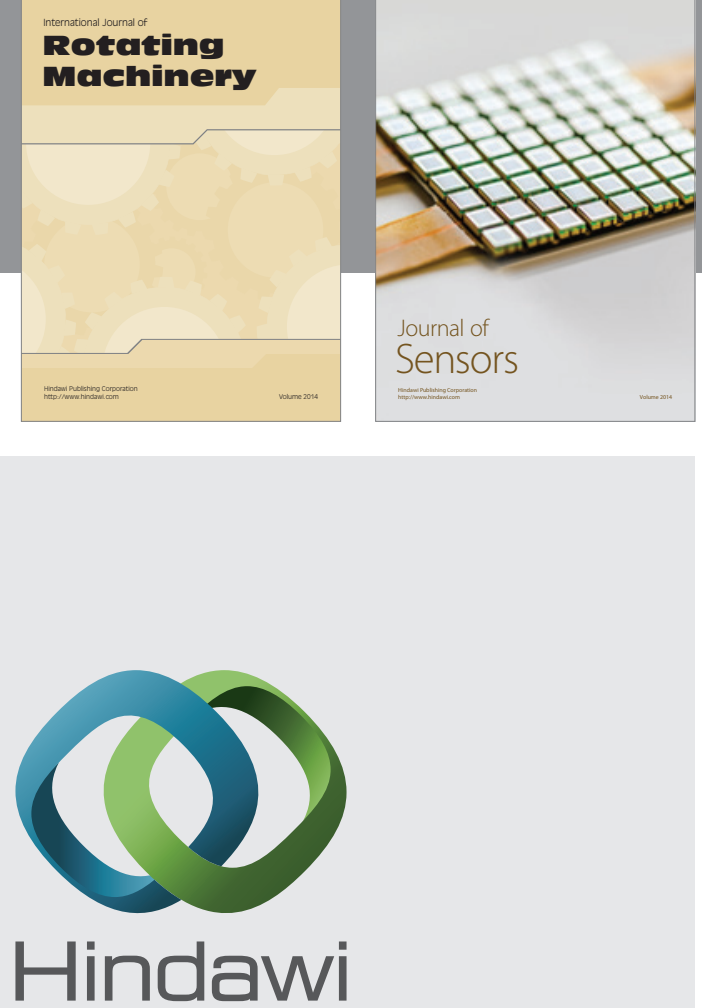

Submit your manuscripts at http://www.hindawi.com
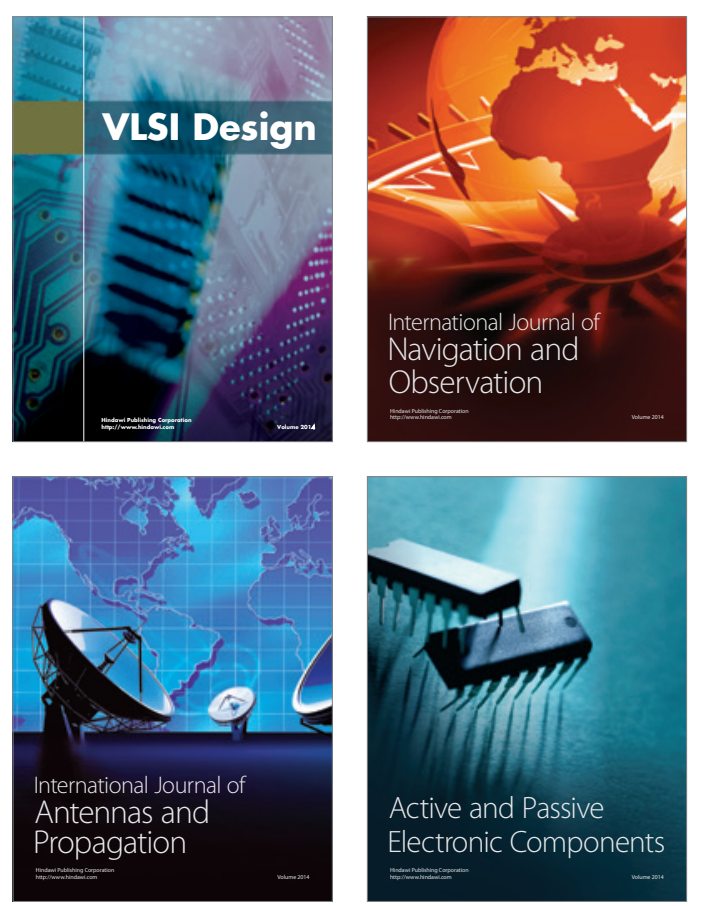
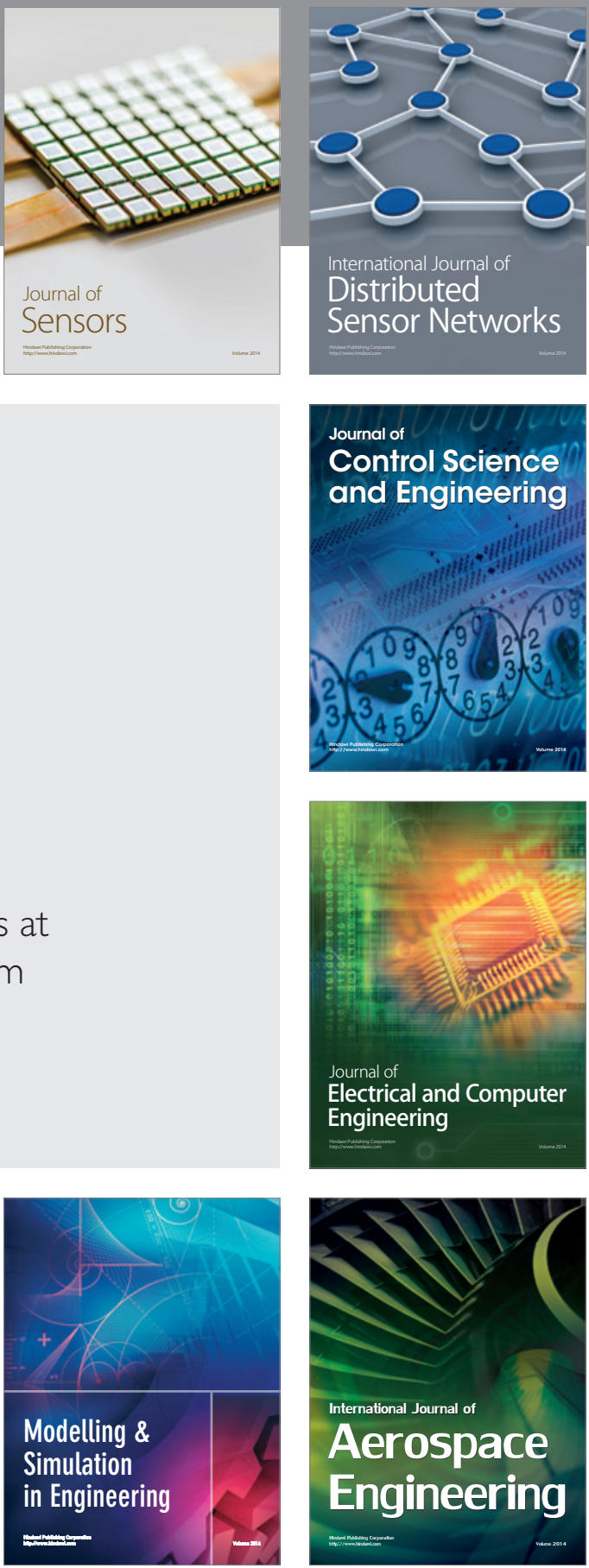

Journal of

Control Science

and Engineering
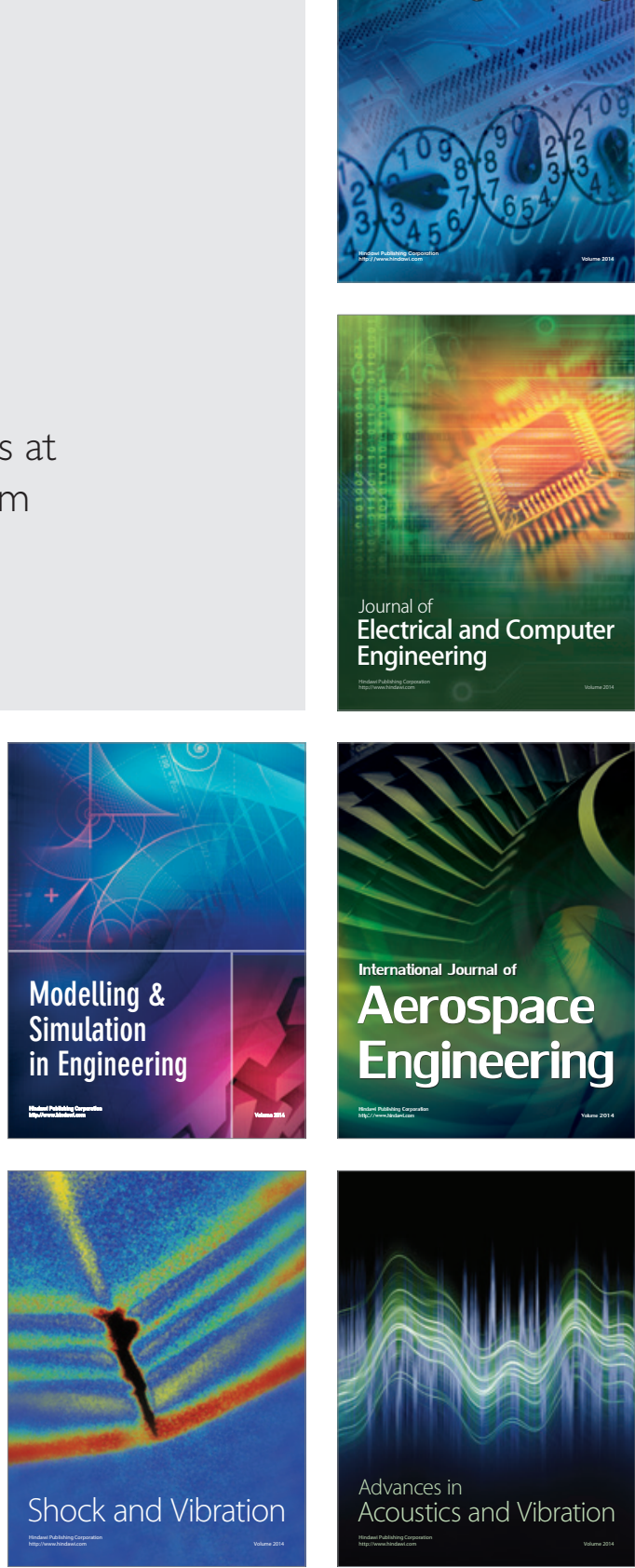